\title{
Resistance in Repressive Contexts: A Comprehensive Test of Psychological Predictors
}

\author{
Arin H. Ayanian \\ Institute for Interdisciplinary Research on Conflict and Violence, Bielefeld University, \\ Germany \\ Email: arin.ayanian@uni-bielefeld.de \\ Nicole Tausch \\ University of St Andrews, Scotland \\ Email: nt20@st-andrews.ac.uk \\ Yasemin Gülsüm Acar \\ University of Dundee, Scotland \\ Email: yacar001@dundee.ac.uk \\ Maria Chayinska \\ Pontifical Catholic University of Chile, Chile \\ Email:m.chayinska@campus.unimib.it \\ Wing-Yee Cheung \\ University of Winchester, United Kingdom \\ Email: WingYee.Cheung@winchester.ac.uk \\ Yulia Lukyanova \\ Newbattle Abbey College, Scotland \\ Email: Yulialukyanova@newbattleabbeycollege.ac.uk
}

Word Count (exc. References, figures and tables): 17987

Author Note

Arin H. Ayanian and Nicole Tausch share lead authorship. All other authors are listed in alphabetic order.

Correspondence should be addressed to Arin H. Ayanian at the Institute for Interdisciplinary Research on Conflict and Violence, Bielefeld University, 33615 Bielefeld; Email: 
arin.ayanian@uni-bielefeld.de or Nicole Tausch at the School of Psychology and Neuroscience, St Mary's Quad, South Street, St Andrews, KY16 9JP; Email: nt20@standrews.ac.uk.

This research was conducted while Arin $\mathrm{H}$. Ayanian was a $\mathrm{PhD}$ candidate at the University of St Andrews, on a full scholarship from the School of Psychology and Neuroscience, University of St Andrews, Scotland. The article was partially written with a PhD stipend granted to Arin H. Ayanian from the International Centre on Nonviolent Conflict, Washington D.C., United States.

The results were presented at the International Society for Political Psychology (ISPP)

Conference in Warsaw Poland in 2016, the small group meeting on "Processes of Radicalization and Polarization in the Context of Transnational Islamist Terrorism: Interdisciplinary Research and Public Implications" in Hannover in 2016, and the small group meeting on "Trajectories of Radicalisation and De-Radicalisation" at the Queensland University in Australia in 2018.

We like to thank Oleskii Shestakovskyi for his valuable help in adapting the questionnaire to the Ukrainian context and translating it to Ukrainian.

(C) 2020, American Psychological Association. This paper is not the copy of record and may not exactly replicate the final, authoritative version of the article. Please do not copy or cite without authors' permission. The final article will be available, upon publication, via its DOI: $10.1037 /$ pspi0000285 


\begin{abstract}
Empirical research on the social psychological antecedents of collective action has been conducted almost exclusively in democratic societies, where activism is relatively safe. The present research examines the psychological predictors of collective action intentions in contexts where resistance is met with significant repression by the authorities. Combining recent advancements in the collective action literature, our model examines the unique predictive roles of emotion (anger and fear), political, identity consolidation and participative efficacies, politicized identification and moral obligation, over and above past participation. It further investigates how these variables are shaped by perceptions of risks due to repression. Four survey studies test this model among protesters in Russia $(N=305)$, Ukraine $(N=136)$, Hong Kong $(N=115)$, and Turkey $(N=296)$. Meta-analytic integration of the findings highlights that, unlike in most current accounts of collective action, protesters in these contexts are not primarily driven by political efficacy. Rather, their involvement is contingent upon beliefs in the ability of protest to build a movement (identity consolidation and participative efficacies) and motivated by outrage at state repression, identification with the social movement, and a sense of moral obligation to act on their behalf. Results also confirm that risks due to state repression spur rather than quell resistance by increasing outrage, politicized identification, identity consolidation and participative efficacies, and moral obligation. The implications of these findings for models of collective action and our understanding of the motives underlying engagement in repressive contexts are discussed.
\end{abstract}

Keywords: Collective action, Risky contexts, Efficacy, Emotions, Politicized identification, Moral obligation 
"I do share part of my life, part of my thinking, part of my ideology with the people around me... I wanted to redress the injustice that was inflicted on us in this country... We were all in this together... getting beaten in the same way... it was likely for any of us to lose his life for the sake of my goal, which is also his goal and all the protesters' goal. It kind of gives that sense of obligation. I didn't mind then to sacrifice my life for the sake of this goal... It's kind of a shared thing between us..."

An Egyptian activist (Ayanian \& Tausch, 2013)

Throughout history, citizens have confronted societal injustices and challenged authoritarian and repressive regimes, often risking arrest, injury, and even their lives. The conditions that give rise to such resistance have been studied widely across the social sciences. The social movement and civil resistance literatures have provided many insights into the macro- and meso-level factors involved by identifying the political and economic contexts and cultural structures that foster (or hinder) mass mobilization, as well as documenting the tactics and stages of resistance campaigns (see Schock, 2013, for a review).

The analytical focus within social psychology has been on the micro-level of analysis; that is, the psychological factors that determine individuals' motivations to participate in such action. Here, an individual is considered to engage in collective action "any time that she or he is acting as a representative of the group and the action is directed at improving the conditions of the entire group" (Wright, Taylor, \& Moghaddam, 1990, p. 995). The socialpsychological literature on collective action is vast and diverse, offering numerous explanations and identifying an array of contributing psychological processes (see van Stekelenburg, Klandermans, \& van Dijk, 2011, for a review). A comprehensive meta-analysis has highlighted three groups of psychological factors that uniquely predict action intentions, namely injustice appraisals and their emotional counterparts, the perceived efficacy of 
collective action, and identification with the aggrieved group or social movement (van Zomeren, Postmes, \& Spears, 2008). Recent refinements have examined the contributions of distinct emotions (e.g., Miller, Cronin, Garcia \& Branscombe, 2009; Tausch, Becker, Spears et al., 2011), distinguished different aspects of efficacy (Hornsey, Blackwood, Louis, et al., 2006; van Zomeren, Saguy, \& Schellhaas, 2013), and examined novel bases of identity (McGarty, Bliuc, Thomas, \& Bongiorno, 2009).

While these developments are informative and inspiring, the research available to date is also limited. In fact, the vast majority of social psychological studies on collective action were conducted in Western, democratic societies, where engagement in protest is relatively risk-free and unlikely to be met with severe repression (for recent exceptions, see Ayanian \& Tausch, 2016; Baysu \& Phalet, 2017; Gulevich, Sarieva, Nevruev, \& Yagiyayev, 2017; Chayinska, Minescu, \& McGarty, 2017). As the factors fostering engagement seem to differ depending on the risks involved (e.g., DiGrazia, 2014; McAdam, 1986; Wiltfang \& McAdam, 1991), it remains unknown how previous findings generalize to high-risk contexts. The present research aims to address this gap in the literature. Specifically, we pursue three main goals: First, across four contexts where activists faced substantial repression from the authorities (Russia, Ukraine, Hong Kong, and Turkey), we test a comprehensive predictive model of collective action intentions, taking into account the roles of distinct emotions (anger and fear), facets of efficacy (political efficacy, identity consolidation efficacy, and participative efficacy), and group identification. Second, to determine how the risks associated with activism feed into the psychological antecedents and impact on willingness to get engaged, we include perceived risks of collective action as a distal predictor in our model. This allows us to assess, from a psychological perspective, the idea that sanctions aimed to discourage participation often backfire and spur further action (see Martin, 2007, 2015; Opp \& Roehl, 1990), and to shed light on the psychological mechanisms 
underpinning this well-documented backlash effect. Finally, we investigate the role of moral obligation, a rarely examined variable in the collective action literature (see Sabucedo, Dono, Alzate, \& Seoane, 2018). A sense of moral obligation emerged as a key motivator in our interviews of activists during the 2011 uprising and 2013 coup in Egypt (Ayanian \& Tausch, 2013). As illustrated in the quote above, moral obligation is closely intertwined with injustice appraisals, instrumental motivations, and shared identities. In line with previous work, we conceptualize moral obligation as the most proximal predictor of action intentions. Before outlining our hypotheses, we review the literature relevant to our research goals.

\section{Core Psychological Drivers of Collective Action}

Three groups of psychological variables, rooted in three theoretical traditions, constitute core motivators that uniquely predict action intentions (see Thomas, Mavor, \& McGarty, 2012; van Zomeren et al., 2008). Relative deprivation theory (Folger, 1986; Runciman, 1966; Walker \& Smith, 2002) has highlighted the importance of shared grievances and emotional responses to deprivation as the catalyst of collective action (see Smith, Pettigrew, Pippin \& Bialosiewicz, 2012). Emotions have received renewed attention with the development of intergroup emotion theory (IET; Gordijn, Wigboldus, \& Yzerbyt, 2001; Mackie, Devos \& Smith, 2000; Mackie \& Smith, 2018; Smith, 1993), which proposes that, in situations where individuals categorize themselves as members of a social group, group-related events become self-relevant and arouse specific group-based emotions together with their associated action tendencies. Justice-related emotions such as anger and outrage, which result from appraisals of unfairness and external blame and arouse confrontational tendencies (Frijda, Kuipers, \& ter Schure, 1989), are widely regarded as central to protest behavior (e.g., van Stekelenburg \& Klandermans, 2007; van Zomeren, Spears, Fischer, \& Leach, 2004). The predictive power of affect was confirmed in van Zomeren et al.'s (2008) meta-analysis, which indicated that measures capturing the affective experience of injustice 
yielded significantly stronger effect sizes than non-affective measures (e.g., perceived disadvantage).

Other emotions that have been considered relevant to group behavior within the intergroup emotions theory framework have received less attention in the collective action literature. Fear in particular, which motivates withdrawal behavior in response to uncertain or threatening events (Dumont, Yzerbyt, Wigboldus, \& Gordijn, 2003; Osborne, Smith, \& Huo, 2012), is relevant in high-risk contexts as it captures the psychological response that underlies deterrence effects (see Saab \& Ayoub, 2017). Experimental work has also suggested that the impact of anger may be overestimated when fear is not considered (Miller et al., 2009).

Complementing this line of work are approaches that focus on the instrumental aspects of collective action. These have considered both internal mobilization resources (e.g., material and human resources; see Gamson, 1992; Klandermans, 1997; McCarthy \& Zald, 1977), as well as (perceived) structural constraints (e.g., the (in)stability of group hierarchy; Tajfel \& Turner, 1979). Psychologically, these manifest as a sense of collective efficacy, defined as "people's collective shared belief of being able to solve their group-related problems by unified effort" (Mummendey, Kessler, Klink, \& Mielke, 1999, p. 232). There is extensive evidence that engagement in collective action is a function of a subjective sense of collective efficacy (e.g., Brunsting \& Postmes, 2002; Berman \& Wittig, 2004; van Zomeren et al., 2004). This is also confirmed in van Zomeren et al.'s (2008) meta-analysis, which yielded a significant positive effect.

The meta-analysis and recent research (Cichocka, Gosrka, Jost, Sutton, \& Bilewicz, 2018; Osborne, Yogeeswaran, \& Sibley, 2015) also indicate, however, that there is substantial heterogeneity for the effect of efficacy. Moreover, some research suggests that general group efficacy is unrelated or even negatively related to intentions to engage in more radical collective action (Tausch et al., 2011). These findings may seem counter-intuitive 
given that collective action is by definition a goal-driven behavior. However, a number of studies have highlighted the importance of defining efficacy (which is typically assessed in terms of political effectiveness) less narrowly and taking into account a variety of motives. Hornsey et al. (2006), for example, demonstrated that the efficacy of collective action is judged according to a range of criteria, including whether protest has the ability to influence third parties, to increase solidarity and facilitate the development of a social movement, or the extent to which it allows expressing one's values, each of which independently predict action intentions. Building on this work, Saab, Tausch, Spears, and Cheung (2015) distinguished political efficacy from identity consolidation efficacy, which conceptualizes the efficacy of action in strengthening the protesting group, and showed that both forms of efficacy play a role in motivating engagement. Van Zomeren et al. (2013) added a further refinement of the efficacy construct. Based on the idea that people might be motivated to "free ride" when the perceived efficacy of collective action is high (Olson, 1968), these authors demonstrated that participative efficacy, defined as an individual's belief that their efforts makes an incremental contribution to action success, adds to the explanation of action intentions.

A third approach emphasizes the importance of identification with the aggrieved group in mobilizing action (Drury \& Reicher, 2000; Reicher, 1996; Tajfel \& Turner, 1979). To the extent that a particular social identity is contextually salient and meaningful, individuals align their beliefs, interest, and behaviors with those of the group (Turner et al., 1987). Social identity theory (Tajfel \& Turner, 1979) further states that identification varies as a function of social-structural factors and is strengthened when one's group is perceived as suffering an illegitimate disadvantage. The awareness of shared grievances and the attribution of blame to an external agent results in the politicization of identities (Simon \& Klandermans, 2001), which are of particular importance for protest behavior as they are accompanied by an internalization of the goals and norms of the social movement (Stürmer \& Simon, 2004). 
Politicized identification has consistently been shown to better predict engagement than identification with the broader disadvantaged group (see van Zomeren et al., 2008).

\section{Moral Obligation as a Proximal Predictor of Engagement}

One aim of the present studies is to demonstrate that injustice, efficacy beliefs and group identification foster action by creating a sense of moral obligation to participate, that is, the belief that taking action is the 'right thing to do' or 'ought to be done' (Vilas \& Sabucedo, 2012). A sense of moral duty or obligation is a central concept in moral philosophy (see Zwart, 1997) and features in many theories of human behavior (Bandura, 1991; Sabucedok, 2002; Zimbardo, 2007). However, only a handful of empirical studies have examined the role of this variable in participation in collective action. For example, Stern, Dietz, Abel, Guagnano, and Kalof (1999) demonstrated that individuals who accept a movement's values, believe that these values are threatened, and believe that their personal actions can help to restore these values, experience an obligation to engage in pro-movement action. Other work has underlined the importance of group processes and social identities in creating this sense of obligation. The devoted actor framework (see Atran, 2016; Atran \& Ginges, 2015), for example, posits that actors in intractable conflicts make decisions to engage in collective action out of a moral duty to protect 'sacred' values embedded in collective identities. Moral obligation is related to but distinct from other morality constructs such as moral values, moral convictions, and inner obligation. Sabucedo et al. (2018) consider moral obligation as the motivation to act according to moral norms and moral convictions. Hence, moral norms and convictions are (more distal) beliefs and moral obligation is "the motivation to act according to them" (Sabucedo et al., 2018, p.3). Three studies confirmed the distinction between these three moral constructs.

In the context of social movements, Stürmer, Simon, Loewy, and Jorger (2003) demonstrated that identification with a social movement (i.e., politicized identification) 
predicts action intentions through an inner obligation to behave in line with group norms. Moreover, inner obligation was unrelated to the reward motive (expected personal gains and losses through participation), in line with the idea that this variable represents an actor's intrinsic motivation. Vilas and Sabucedo (2012) tested an integrative model of the role of moral obligation in motivating collective action. They demonstrated that student's anger about an alleged rise in tuition fees, identification with the student movement against fees, and beliefs in the efficacy of collective action independently predict a sense of moral obligation, which emerged as the strongest predictor and mediated the link between these variables and action intentions. The recent work by Sabucedo et al. (2018) further indicated that moral obligation is the strongest predictor of actual participation. We aim to contribute to this emerging field within the collective action literature by providing additional empirical evidence for the role of moral obligation, considering it as the most proximal predictor of collective action, including novel predictors which have not been included in the above mentioned studies (i.e., perceived risks, fear, identity consolidation efficacy, and participative efficacy), and looking at this in repressive contexts.

\section{Collective Action in High-Risk Contexts}

The term risk refers to specific adverse effects that might occur only if one decides to engage in a particular behavior (Fischhoff, Watson, \& Hope, 1984; Luhmann, 1991; Renn, 1992). Based on McAdam (1986), we define high-risk activism as activism in contexts where engagement is associated with severe anticipated dangers, including legal (e.g., being arrested), financial (being fined), or physical (being injured or killed) risks. Note that risks are conceptually different from costs, which are circumscribed and may refer to the energy, time, and financial losses incurred through engagement (Klandermans, 1984). As noted by McAdam (1986), low-cost actions such as signing a petition can be high-risk in contexts where doing so can have detrimental personal consequences, as it did recently for many 
Turkish academics who were convicted of terrorism charges after signing a petition to end government violence against the Kurds (Acar \& Coşkan, 2020; Başer, Akgönül, \& Öztürk, 2017).

The sociological and political science literatures on social movements and civil resistance provide two key insights relevant to the present work. First, a series of studies underline the importance of distinguishing the factors underpinning individual involvement in high- vs low-risk activism. For example, McAdam (1986) showed that the progression from low- to high-risk activism depends to a large extent on the presence of strong social ties to other activists, as well as the depth of ideological commitment (see also Nepstad \& Smith, 1999; Wiltfang \& McAdam, 1991). Similarly, DiGrazia (2014) reported that those from privileged social backgrounds and ideologically moderate are more likely to engage in lowrisk activism and those from disadvantaged social groups and ideologically more extreme are more likely to engage in high-risk activism. These findings underline the importance of expanding tests of established predictive models to high-risk contexts.

Second, a large body of work demonstrates that the relationship between repression and activism does not necessarily conform to the intuitive assumption that greater risks quell resistance. While approaches relying on an economic model of protest behavior (e.g., Olson, 1965; Hardin, 1982) view risks faced through participation as disincentives that should reduce activism (see also Boykoff, 2007), approaches highlighting the importance of collective processes suggest that repression is likely to create new grievances (e.g., Gurr, 1970), increase other incentives attached to engagement (e.g., social, moral and public goods incentives; see Opp, 1994, White, 1989), and may thus aid the very processes that enable successful mass mobilization, such as consciousness-raising and framing (Hirsch, 1990).

Empirical research on this topic has mostly conducted macro- and meso-level analyses and examined the impact of state repression on the rate of social protest over time and cross- 
nationally, as well as the effects of acts of repression on specific social movements (see Earl, 2011 , for a review). There is some evidence demonstrating deterrence effects at the macrolevel (e.g., Earl \& Soule, 2010; Koopmans, 1997), as well as findings showing that repression weakens social movement organizations (e.g., Jeffries, 2010). A substantial body of research has, however, documented an escalation of protest activity (Francisco, 1995, 2004; Jenkins \& Schock 2004; Ondetti, 2006; Ortiz, 2007; Rasler, 1996; White, 1989). Consistent evidence was also reported at the meso-level, where repression was shown to foster alliances (Chang, 2008; Chang \& Kim, 2007; Loveman, 1998), and to strengthen movements by increasing public and international support (DeNardo, 1985; Hess \& Martin, 2006).

Linking these political outcomes with individuals' responses, Opp and Roehl (1990) argue that negative sanctions are likely to indirectly stimulate protest by setting in motion processes of "micro-mobilization" (p.523), which increase individuals' motivation and commitment (see also White, 1989). Empirical analyses of such micro-level processes are, however, scarce (see Earl, 2011; Honari, 2017). Opp and Roehl (1990) demonstrated that expectations of police brutality predicted greater willingness to protest among German antinuclear power protesters by creating a sense of political alienation, which Opp and Roehl (1990) define as when the political system is considered with discontent and a critical eye, increasing expected approval of protest by close others, and heightening obligation to participate (see also Linden \& Klandermans, 2007, for qualitative data). Only one study has examined the impact of risk from a social-psychological perspective. Ayanian and Tausch (2016) provided first evidence that perceived risk (i.e., the perceived likelihood of being arrested, injured or killed) was a positive predictor of action intentions in the post-coup uprising in Egypt, over and above current involvement. Furthermore, this relation was in part mediated by outrage about the treatment of protesters and increased identity consolidation efficacy (i.e., the perceived effectiveness of protest in building a social movement). 


\section{Hypotheses}

The present research aims to further illuminate the psychological processes that motivate individuals to protest in repressive, high-risk contexts by testing a predictive model derived from the main social-psychological theories of collective action and incorporating recent theoretical advancements. Our model considers risk perception as a distal predictor, emotional responses to risk (fear and anger), facets of the efficacy of protest (political, identity consolidation, and participative efficacy), and politicized identification as mediating variables, and moral obligation as the most proximal predictor of future action intentions (see

Figure 1). To the best of our knowledge, the present predictive model is the first to consider these variables simultaneously to assess their unique contributions.

Based on intergroup emotions theory (e.g., Mackie et al., 2000) and previous work (Saab \& Ayoub, 2016), we expect that perceived risks due to repression (i.e., expectations that engaging in protest results in negative consequences such as arrest or injury) to positively predict fear (H1). We also expect a positive link between perceived risks and outrage $(\mathrm{H} 2)$, based on the idea that sanctions imposed by the authorities constitute new grievances (Gurr, 1970; Hess \& Martin, 2006; see also Ayanian \& Tausch, 2016). We afford alternative hypotheses regarding the relation between perceived risks and efficacy. On the one hand, perceived risks might negatively predict political efficacy $(\mathrm{H} 3 \mathrm{a})$, as protesters can perceive repression as authorities' determination and ability to resist their demands (Muller, 1985). Similarly, the expectations of such sanctions might reduce perceived identity consolidation efficacy (H4a), as severe reprisals against protesters could reduce social action support (van Zomeren et al., 2004) and thus reduce the movement's mobilization potential. By the same logic, increased risks attached to protest might also diminish belief in the value of one's own contribution (H5a). Perceived risks may, however, also increase the expected political efficacy of protest (H3b). Repression can signal the authorities' weakness, as they are losing 
the people's voluntary compliance (Chenoweth, 2015; Sharp, 2005) and impose international pressure on the authorities to concede to protesters' demands (Dudouet, 2015; Ondetti, 2006; Wisler \& Giugni, 1999).

As protest under repressive conditions can arouse sympathy and support from bystanders and motivate yet uninvolved people to join in (DeNardo, 1985), one might also expect a positive relation between risk and identity consolidation efficacy ( $\mathrm{H} 4 \mathrm{~b}$; see Ayanian \& Tausch 2016, for initial evidence). This mobilizing effect forms part of the strategy of many radical movements, which are often successful in engendering wider support for their goals due to excessive countermeasures by the state (see Kydd \& Walter, 2006). The belief in the added value of one's own contribution (participative efficacy) might also be positively predicted by imposed risks (H5b), as repression reduces the ability to 'free ride' and is likely to highlight the importance to demonstrate strength (Lukyanova, 2016; Smyth, Soboleva, Shimek, \& Sobolev, 2013). We further hypothesize perceived risks to increase politicized identification (H6) based on the idea that illegitimate group-based disadvantages, such as perceived risks due to authority repression, create perceptions of common fate, which lead activists to feel closer to other protesters, increase their belonging and psychological investment in the group, and prioritize their group's interests (Della Porta, 1992; Drury \& Reicher, 2000; Reicher, 1996).

Based on previous research, we expect the core predictors of collective action to feed into a sense of moral obligation. First, we hypothesize a positive relation between politicized identification and moral obligation (H7), in line with the idea that identification with a social movement creates an experienced duty to conform to group norms and protect ingroup values (Atran \& Ginges, 2015; Stürmer et al., 2003; Vilas \& Sabucedo, 2012). Moreover, the belief that one's personal actions can make a contribution (see Stern et al., 1999), and that protests serve to build and solidify the movement, should be associated with a heightened sense of 
obligation (H8 and $\mathrm{H} 9$, respectively). We propose alternative hypotheses regarding the relation between political efficacy and moral obligation. One the one hand, the belief that the action will be successful in achieving its goals might create a greater imperative to join in (H10a; see Vilas \& Sabucedo, 2012). On the other hand, high perceived political efficacy might compel individuals to "free-ride" (Olson, 1968) as there is less of a perceived need to contribute $(\mathrm{H} 10 \mathrm{~b})$.

Based on previous findings indicating that a sense of obligation rises as a function of perceived severity of an offense (Stern et al., 1999; Vilas \& Sabucedo, 2012), we hypothesize a positive link between outrage and moral obligation (H11). We have no expectations regarding the link between fear and moral obligation, but propose that fear will be a direct negative predictor of collective action intentions (H12), in line with the established association of fear with cautious and risk-averse behavior (Lerner \& Keltner, 2000, 2001; Smith \& Kirby 2001), as well as with previous work which demonstrated fear's predictive role in withdrawal behavior (Dumont, et al., 2003; Miller et al., 2009; Saab \& Ayoub, 2016). Finally, we expect moral obligation to be a positive predictor of action intentions (H13; see Stern et al., 1999; Stürmer et al., 2003; Vilas \& Sabucedo, 2012; Vilas et al., 2018). As previous research has reported mixed findings regarding the role of moral obligation as a full or partial mediator (see Stürmer et al., 2003; Vilas \& Sabucedo, 2012; Sabucedo et al., 2018), we allow residual paths from all predictors to collective action intentions in our model.

We tested our predictions in four political contexts where collective action was repressed by the authorities: protests demanding political reform in Russia (Study 1), the Ukrainian protests against the separation of the South-Eastern regions (Study 2), protests that took place as part of the Umbrella movement in Hong Kong (Study 3), and the protests against urban regeneration projects in Turkey (Study 4). The findings of these studies are then summarized meta-analytically. In each study we used participants' own willingness to 
engage in collective action as our main dependent measure. Previous research has shown that behavioral intentions can be a useful proxy for actual behavior (Webb \& Sheeran, 2006) and that collective action intentions are good predictors of actual participation (e.g., de Weerd \& Klandermans, 1999; Moskalenko \& McCauley, 2009).

Furthermore, in each study, we focus primarily on individuals who were already or who are likely to be involved in the protest movements under investigation, but with varying degrees of engagement, since we were particularly interested in examining how risks shape one's motivation to engage in collective action pertinent to them. Our choice was based on our acknowledgment that within the general population, individuals might respond differently to the grievances raised during protests and to the state repression, as some would strongly disagree with the protests' demands and even applaud state repression. We include past participation as a control variable for all hypothesized associations. Thus, the impact of risks represent shifts in action intentions (over and above previous levels of involvement), as a function of emotions in response to repression, efficacy beliefs, identity, and moral obligation. Hence, this inclusion controls for potential differences between participants with different levels of involvement and investment in protests (e.g., heavily involved activists, recently engaged activists, occasional protesters), and excludes the potential differences between occasional and heavily involved activists due to their rating the constructs differentially. 


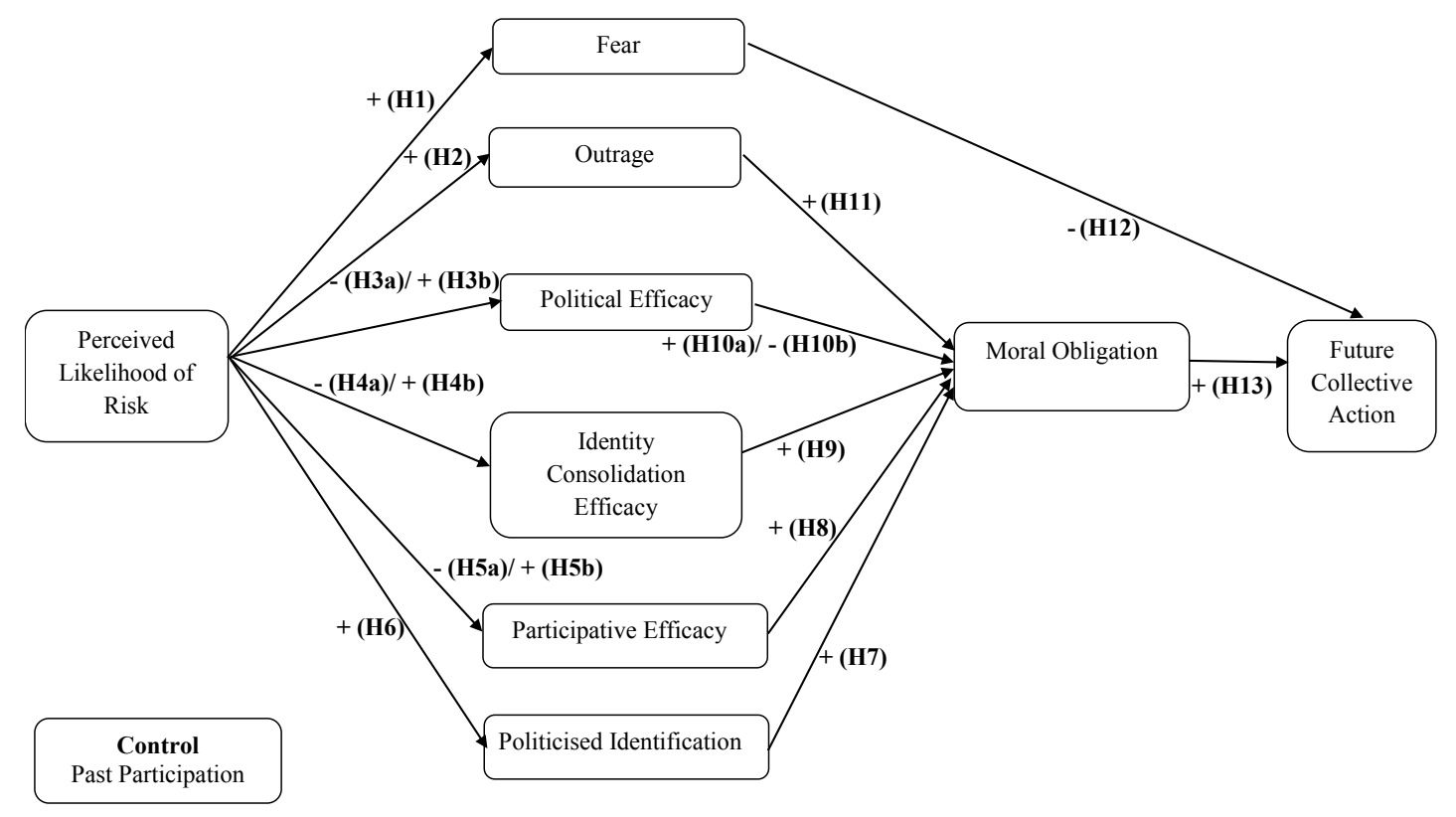

Figure 1: Summary of hypotheses

\section{Study 1: Russia}

Russia witnessed a wave of protests in response to the 2011-2012 legislative and presidential elections, which were perceived by many as illegitimate and fraudulent (Gel'man, 2015; Ross, 2015). Initially of a small scale, the protests escalated into massive demonstrations in Moscow and across the country. The protesters demanded political and economic reforms; they called for political prisoners to be freed, political freedoms to be respected and broadened (e.g., allowing the registration of opposition parties), and corruption to end. These protests were met with substantial repression. The authorities arrested hundreds of protesters and imprisoned some of the main protest leaders (Greene, 2014). In June 2012, new laws were implemented to impose heavy penalties for any collective action that is not sanctioned by the authorities. Specifically, a new law determined that anyone who tries to threaten the integrity of Russia, even if such threats are made solely in online forums, can be imprisoned for up to five years (Demirjian, 2014). Furthermore, several websites were censored and even blocked for documenting the authorities' breaches of human rights 
(Greene, 2014) and several opposition leaders were harassed and NGOs involved in the actions were scrutinized (International Federation for Human Rights and Anti-Discrimination Centre, 2014; Lyytikainen, 2013). In the time period during which we conducted the survey (early May 2014), Russian activists were attempting to organize the annual May 6 protests in support of the goals of the 2011-2012 movement.

\section{Method}

\section{Procedure and Respondents}

We received the ethical approval for this study (and the three subsequent ones) from the school research ethics committee at the University of St Andrews. We launched the survey on May $2^{\text {nd }} 2014$, four days prior the planned May 6 protests. The link to the online survey was sent to a group of activists who had participated in a previous interview study on political activism conducted by one of the authors, and posted on one of the pro-oppositional radio station's website called Echo of Moscow. A total of 433 participants entered the survey. We deleted the data of 125 participants who either left the survey immediately before completing any measures, completed the demographics items only, filled in measures for just one or two of the focal constructs, or had scattered data points but left $90 \%$ of the survey empty. We also deleted three multivariate outliers identified through Casewise diagnostic (standardized residuals $> \pm 2.5$ ), leaving a final sample of 305 participants (153 women, 151 men, one refused to answer; $\left.M_{\text {age }}=37.60, S D=11.74\right)$. Most participants $(46.7 \%)$ were from Moscow, and nearly all (93.3\%) had completed higher education. The majority of participants had some level of past participation in collective action; $2 \%$ were protest organizers, $9.5 \%$ were regular protesters, $43.3 \%$ were occasional protesters, and $21.3 \%$ were active on social networks. 


\section{Measures}

Two bilingual students translated and back-translated the survey into Russian. Participants completed measures of the main variables, demographics, and series of questions about the political situation in Russia, which are not part of this analysis. The full list of analyzed items for all four studies can be found in the Supplementary Material.

Likelihood of risk. Participants indicated the perceived risks of protesting using seven items on five-point scales ranging from very unlikely (1) to very likely (5) (i.e., "risking employment or university degree", "being harassed by the police", "a family member being harassed by the police (losing privileges, e.g., jobs)", "being arrested", "being imprisoned, detained", "being tortured", "being killed", $\alpha=.92$, adapted from Ayanian \& Tausch, 2016, and Opp, 1994).

Politicized identification. Participants rated five items on five-point scales ranging from 1 (strongly disagree) to 5 (strongly agree) (e.g., "I feel I belong to the protest Movement in Russia", "being part of the protest movement in Russia is an important part of who I am", $\alpha=.92$; adapted from Cameron, 2004).

Efficacy beliefs. We adapted Saab et al.'s (2015) scale to assess political and identity consolidation efficacies by asking participants how likely it was for the protests to realize a range of goals $(1=$ very unlikely to $5=$ very likely $)$. Our political efficacy ${ }^{1}$ scale included ratings of nine goals relating to the explicit goals of the protest (e.g., "end of corruption in Russia", "registration of oppositional parties", "defense of human rights", $\alpha=.93$ ). To assess identity consolidation efficacy we asked respondents to rate three goals (i.e., "increase public

\footnotetext{
${ }^{1}$ Across the four studies, the items for political efficacy were adapted to each context to reflect the explicit goals of each movement based on consultations with the collaborators who were experts on the protest movement in their respective context.
} 
support for the protests in Russia", "strengthen the solidarity among the protesters", "ensure international support for the protests in Russia", $\alpha=.77$ ).

Participative efficacy. We used two items adapted from van Zomeren et al. (2013) to measure participative efficacy (e.g., "I believe that I, as an individual, can contribute greatly so that members of the opposition movement in Russia, as a group, can achieve their goals", $r$ $=.76, p<.001)$ on scales ranging from $(1)=$ strongly disagree to $(5)=$ strongly agree.

Outrage. On a five-point scale ranging from not at all (1) to a great extent (5), participants rated the extent they feel outraged (i.e., "When thinking about the treatment of protesters in Russia (e.g. arrestment, use of force, use of tear gas and pepper spray, etc...), to what extent do you feel outraged?").

Fear. On a five-point scale ranging from not at all (1) to a great extent (5), participants rated the extent to which they feel fearful (i.e., "When thinking about protesting against the government, please indicate the extent to which you feel the following emotions when you engage in non-violent sanctioned collective action ${ }^{2}$ (i.e., peaceful protests, peaceful demonstrations, peaceful sit ins, etc.).

Moral obligation. Participants rated how obliged they felt to participate in collective action by rating four items on five-point scales ranging from 1 (strongly disagree) to 5 (strongly agree) (e.g., "I feel morally obliged to participate in anti-government protests", "I

\footnotetext{
${ }^{2}$ We decided to consider peaceful sanctioned collective action, referring to actions (e.g., demonstrations, protests, etc.) that have received prior approval from the authorities, as the May 6 protests were expected to be sanctioned. Moreover, the majority of activists in Russia engage in such collective action, and, although officially sanctioned, these actions were still repressed by the authorities (see Barry \& Schwirtz, 2012; Krasavina, 2017).
} 
feel a strong sense of responsibility to participate in the anti-government protests", $\alpha=.95$; adapted from Vilas \& Sabucedo, 2012).

Action intentions. Participants rated their likelihood to engage in sanctioned peaceful collective action using a single item on a five-point scale ranging from definitely will not take part (1) to I will definitely take part (5) (e.g., "Please tell us how likely it is that you would engage in sanctioned, non-violent protest actions (e.g., protesting, demonstrating, being active on social networks) in the very near future") $)^{3}$.

Control variables. Participants' level of involvement in past protests, assessed on a single five-point scale ranging from never (1) to frequently (5), as well as their age (in years) were included as control variables in the path model.

\section{Results and Discussion}

Preliminary analyses and general analytical strategy. We employed path analysis in M-Plus (Version 5.2; Muthén \& Muthén, 1998, 2007) to assess the significance of the proposed relations and evaluate the significance of indirect paths in one step. Demographic variables were included as controls when they correlated with the model variables to avoid spurious relationships. Prior to the analyses we first inspected our data with respect to missing values and normality. Due to missing data on a number of variables (see details below) as well as diversions from normality for some variables, we decided to use bootstrapping for our path analyses in all studies and used bootstrap standard errors and bias-

\footnotetext{
${ }^{3}$ We conducted factor analyses for a three-factor versus a one-factor model to test whether politicized identification, moral obligation and collective action are in fact three distinct constructs. Across the four studies, our results confirmed that the three factor solution provided a significantly better fit than the alternative one-factor model.
} 
corrected confidence intervals based on 5,000 resamples for all parameter estimates (Efron \& Tibshirani, 1993; Preacher \& Hayes, 2008).

Means, standard deviations and Pearson correlations between the model variables for the present study are presented in Table 1. Participant age correlated significantly with several model variables and was thus included as a control. In Table 2 we present the means and standard deviations for responses to each individual item related to perceived risks. The table suggests that participants perceived these risks as relevant, since except for the items of being tortured and killed, participants scored significantly higher than the midpoint.

Note that age (7.5\%), fear (39.7\%), moral obligation (22.3\%), and willingness to engage in collective action (18\%) had notable proportions of missing values. The amount of missing data for other variables was negligible ( $<5 \%)$. Little's (1988) global test, which determines whether missing values depend on other model variables, was non-significant $\left(\chi^{2}\right.$ $(1050)=1119.094, p=.068)$, suggesting that the overall missing data pattern can be considered missing-completely-at-random (MCAR; Little \& Rubin, 2002). Nonetheless, further inspection indicated that past involvement in protest negatively correlated with missingness for fear $(r=-.55, p<.01)$, suggesting that those who were less highly involved in protests had difficulty answering some of the questions related directly to activism (e.g., how fearful would they be while protesting). Thus, we considered the missing data as missing-at-random (MAR ${ }^{4}$; see Rubin, 1976) and employed full information maximum-

\footnotetext{
${ }^{4}$ Missing completely at random (MCAR) is when the missing points do not depend on observed nor unobserved data (Little \& Rubin, 2002). Missing at random (MAR) is when the missingness depends on observed data but not unobserved data. Hence, it refers to missing value patterns where there are systematic relationships between the missing values and the data included in the analyses (Graham, 2009; Little \& Rubin, 2002). Missing not at random
} 
likelihood estimation (FIML; Enders, 2001) in the analyses. This method uses all available information to provide a maximum likelihood estimate for missing values and thus adjusts for likely mechanisms of missingness and includes in the model variation accounting for the missing values. FIML was shown to produce the least biased results compared to traditional methods of handling missing data such as listwise deletion or mean imputation (Acock, 2005, Schafer \& Graham, 2002). Although we note few differences in results between this method and listwise deletion ${ }^{5}$, results from listwise deletion should be approached with caution. As listwise deletion yields conservative results and loss of power, it inflates the standard errors and reduces the significance when MCAR is met, and it yields biased estimates when MAR is met (Buhi, Goodson, \& Neilands, 2008; Enders, 2001).

(MNAR) is when the missingness depends on unobserved variables rather than variables included in the analyses.

${ }^{5}$ Listwise deletion of cases with missing values yielded a reduced sample of $N=137$. While the overall pattern of results was very similar, several of the paths did not reach conventional levels of significance. Specifically, perceived risks did not predict participative efficacy $(B=$ $-.03, S E=.11, p=.979,[-.221, .215])$, and outrage did not predict moral obligation $(B=.07$, $S E=.05, p=.156,[-.029, .177])$. The direct paths from outrage $(B=.08, S E=.06, p=.138$ $[-.028, .197])$ and participative efficacy $(B=.00, S E=.08, p=.985,[-.158, .161])$ to collective action were also not significant. The indirect paths from perceived risks to collective action via outrage and participative efficacy were not significant $(.03, S E=.03, p$ $=.200,[-.000, .097] ; .00, S E=.01, p=.999,[-.018, .017])$. The indirect $(.13, S E=.08, p$ $=.213,[-.020, .302])$ and total $(-.04, S E=.09, p=.654,[-.022, .139])$ paths from perceived risks to collective action were also not significant. 
Table 1: Means, Standard Deviations, and Zero-order Correlations (Study 1)

\begin{tabular}{|c|c|c|c|c|c|c|c|c|c|c|c|c|c|}
\hline & Mean & $\mathrm{SD}$ & 1 & 2 & 3 & 4 & 5 & 6 & 7 & 8 & 9 & 10 & 11 \\
\hline 1. Likelihood of Risk & 3.39 & .91 & 1.000 & & & & & & & & & & \\
\hline 2. Outrage & 3.33 & 1.36 & $.36^{* *}$ & 1.000 & & & & & & & & & \\
\hline 3. Fear & 2.16 & .98 & $.36^{* *}$ & .14 & 1.000 & & & & & & & & \\
\hline 4. Political Efficacy & 2.60 & .79 & $-.16^{*}$ & .05 & -.09 & 1.000 & & & & & & & \\
\hline $\begin{array}{l}\text { 5. Identity Consolidation } \\
\text { Efficacy }\end{array}$ & 3.40 & .83 & $.13^{*}$ & $.24 * *$ & .06 & $.40 * *$ & 1.000 & & & & & & \\
\hline 6. Participative Efficacy & 2.77 & 1.07 & $.17 * *$ & $.27 * *$ & .04 & $.35^{* *}$ & $.39 * *$ & 1.000 & & & & & \\
\hline 7. Politicized Identification & 3.10 & .99 & $.41 * *$ & $.46^{* *}$ & .14 & $.12^{*}$ & $.39^{* *}$ & $.58 * *$ & 1.000 & & & & \\
\hline 8. Moral Obligation & 3.31 & 1.19 & $.34 * *$ & $.43 * *$ & -.02 & .03 & $.23^{* *}$ & $.54 * *$ & $.73^{* *}$ & 1.000 & & & \\
\hline 9. Future Collective Action & 3.25 & 1.17 & $.19 * *$ & $.42 * *$ & $-.20 * *$ & $.14^{* *}$ & $.32 * *$ & $.54 * *$ & $.68 * *$ & $.73 * *$ & 1.000 & & \\
\hline 10. Past Involvement & 2.38 & 1.17 & $.14^{*}$ & $.31 * *$ & .01 & $.16^{* *}$ & $.20^{* *}$ & $.45^{* *}$ & $.52 * *$ & $.62 * *$ & $.65^{* *}$ & 1.000 & \\
\hline 11. Age & 37.60 & 11.74 & .09 & $.19 * *$ & $-.16^{*}$ & .05 & .02 & $.14 *$ & $.29 * *$ & $.28 * *$ & $.22 * *$ & $.17 * *$ & 1.000 \\
\hline
\end{tabular}


Table 2: Means, Standard Deviations for Perceived Risks (Study 1)

\begin{tabular}{ll}
\hline \hline Perceived Risks & $M(S D)$ \\
\hline Risking employment/or university degree & $3.56(1.07)$ \\
Being harassed by the police & $3.94(.95)$ \\
Having a family member being harassed by the police (losing & $3.20(1.12)$ \\
privileges, e.g. jobs...) & \\
Being Imprisoned, detained etc. & $3.86(1.02)$ \\
Being Arrested & $3.60(1.11)$ \\
Being tortured & $2.96(1.22)$ \\
Being killed & $2.65(1.19)$ \\
\hline Note: The items were rated on five-point scales ranging from very unlikely $(1)$ to very likely
\end{tabular}
(5)

Path analysis. The results of our path analysis are summarized in Figure 2 (see Table S1 in the Supplementary Material for detailed reports of all direct, indirect and total effects). As predicted, perceived risks positively predicted fear $(\mathrm{H} 1 ; B=.36, S E=.05, p<.001$, $[.273, .462])$, outrage $(\mathrm{H} 2 ; B=.48, S E=.08, p<.001,[.329, .642])$, participative efficacy $(\mathrm{H} 5 \mathrm{~b} ; B=.14, S E=.06, p=.020,[.016, .253])$, and politicized identification (H6; $B=.34$, $S E=.05, p<.001,[.238, .435])$. Contrary to hypothesis $\mathrm{H} 4$, perceived risks did not predict identity consolidation efficacy $(B=.10, S E=.06, p=.088,[-.016, .217])$. Confirming hypothesis $\mathrm{H} 3 \mathrm{a}$ and in line with the idea that increased sanctions reduce the belief that protest's demands will be met (Muller, 1985), perceived risks negatively predicted political efficacy $(B=-.17, S E=.05, p=.002,[-.272,-.064])$. There was also a significant direct link between perceived risks and moral obligation to participate $(B=.09, S E=.04, p=.028$, $[.010, .176])$

As expected, politicized identification $(\mathrm{H} 7, B=.50, S E=.06, p<.001,[.367, .623])$, participative efficacy $(\mathrm{H} 8, B=.21, S E=.05, p<.001,[.110, .319])$ and outrage $(\mathrm{H} 11, B=.11$, $S E=.03, p<.001,[.053, .182])$ positively predicted moral obligation. Contrary to H9, identity consolidation efficacy $(B=-.03, S E=.05, p=.579,[-.129, .078])$ did not predict moral obligation. Interestingly and consistent with hypothesis $\mathrm{H} 10 \mathrm{~b}$, political efficacy $(B=$ $-.13, S E=.05, p=.007,[-.236,-.038])$ negatively predicted moral obligation and had an 
indirect negative path to collective action through moral obligation $(-.04, S E=.02, \mathrm{p}=.031$, $[-.091,-.011])$. This is consistent with the "free rider effect" (Olson, 1968); thus, the more likely individuals felt that the protest movement will achieve its goals, the less they felt an obligation to take action.

Consistent with H12, fear $(B=-.24, S E=.05, p<.001,[-.338,-.123])$ negatively predicted action intentions. There were also direct paths from outrage $(B=.11, S E=.03, p$ $<.001,[.056, .182])$, identity consolidation efficacy $(B=.12, S E=.05, p=.013$, $[.021, .203])$, participative efficacy $(B=.10, S E=.05, p=.031,[.011, .200])$, and politicized identification $(B=.30, S E=.07, p<.001,[.161, .441])$ to action intentions. Finally, and consistent with H13, moral obligation $(B=.31, S E=.07, p<.001,[.184, .447])$ positively predicted collective action intentions. The model explained a sizeable $70 \%$ of the variance in collective action intentions.

Analyses of the indirect effects indicated that while perceived risks negatively predicted action intentions through fear $(-.09, S E=.02, p=.001,[-.142,-.043])$, in line with a deterrent effect, there were positive indirect effects via outrage $(.06, S E=.02, p=.003$, $[.025, .100])$, participative efficacy $(.01, S E=.01, p=.141,[.001, .043])$, politicized identification $(.10, S E=.03, p<.001,[.054, .163])$, and moral obligation $(.03, S E=.01, p$ $=.048,[.005, .064])$. Notably, the total effect from perceived risks to collective action was positive and significant $(.13, S E=.06, p=.023,[.020, .250])$, confirming the idea that sanctions related to activism can galvanize people to engage in further action (Opp \& Roehl, 1990; White, 1989). 


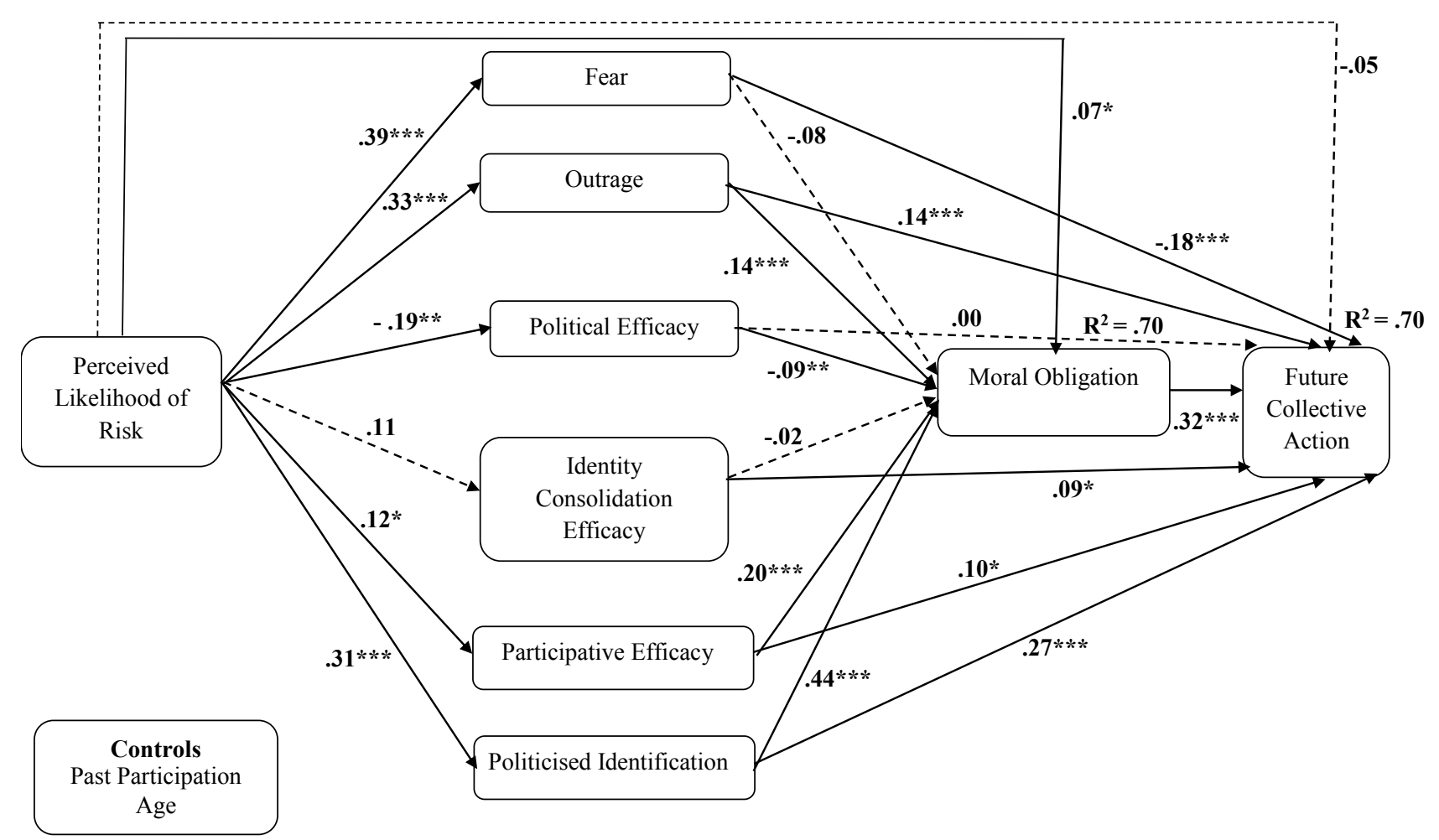

Figure 2: Results of path analysis in the Russian sample (Study 2, $N=308$ ). The dashed arrows are the non-significant paths. The coefficients are the standardized regression estimates. ${ }^{*} \mathrm{p}<.05,{ }^{*} \mathrm{p}<.01, * * * \mathrm{p}<.001$. Past involvement in protests and age were considered as covariates. Past involvement positively predicted outrage $(\beta=.24)$, political efficacy $\left(\beta=.19^{* *}\right)$, identity consolidation efficacy $\left(\beta=.19^{* *}\right)$, participative efficacy $(\beta$ $=.42 * * *)$, politicized identification $\left(\beta=.47^{* * *}\right)$, moral obligation $(\beta=.28 * * *)$, and collective action $\left(\beta=.20^{* * *}\right)$. Past participation negatively predicted fear $\left(\beta=-.16^{* *}\right)$. Age positively predicted outrage $\left(\beta=.12^{*}\right)$ and politicized identification $\left(\beta=.17^{* *}\right)$, and negatively predicted fear $(\beta=-.21 * * *)$.

Overall, these findings confirm the importance of politicized identification, emotions, and efficacy beliefs in predicting collective action intentions in a high-risk context. Identification with the protest movement emerged as the strongest predictor and, in line with prior research (Stürmer et al., 2003), its effect was partially mediated by obligation to participate. The significance of this variable also mirrors qualitative findings based on interviews with Russian activists (Lukyanova, 2016; Smyth, Soboleva, Shimek, \& Sobolev, 2013a, 2013b), which highlighted psychological investment in the movement and emotional 
ties with fellow activists as key motivators for participation. Consistent with predictions based on intergroup emotions theory and previous research (Dumont et al., 2003; Miller et al., 2009; Saab \& Ayoub, 2016), fear experienced in relation to repression of protest negatively predicted collective action intentions, while outrage about the treatment of protesters positively predicted action intentions (as in Ayanian \& Tausch, 2016), both directly and indirectly via moral obligation.

The predictive roles of the different types of efficacy were more complex. There was a small predictive effect of identity consolidation efficacy, suggesting that the perceived ability of a protest in mobilizing a movement contributes to people's decisions to get involved. This replicates Ayanian and Tausch's (2016) findings from a study of the Egyptian uprising and supplements qualitative interview data in the context of current Russian antigovernment activism in which activists stressed the importance of the protests in reaching the wider population and establishing alliances with other organizations (Lukyanova, 2016; Smyth et al., 2013a, 2013b). Furthermore, the novel construct of participative efficacy (van Zomeren et al., 2013) uniquely predicted action intentions, both directly and indirectly via moral obligation. Thus, the extent to which potential protesters believe in the importance of their personal contribution, the more obliged they feel to participate, and the more willing they are to get involved, over and above the 'traditional' predictors of engagement.

Finally, an intriguing finding emerged with regard to the predictive role of political efficacy, which had a negative indirect effect on action intentions via moral obligation. Instrumental accounts of collective action generally assume, and copious evidence confirms (e.g., Mummendey et al. 1999; Saab et al, 2015; see van Zomeren et al., 2008, for metaanalytic evidence), that political efficacy is a major motivator for individual participation. Several recent studies have, however, reported negative relations between political efficacy and action intentions (Ayanian \& Tausch, 2016; Tausch et al., 2011; van Zomeren et al., 
2013). A number of explanations for this effect have been proffered. Some authors (Saab, Spears, Tausch, \& Sasse, 2016; Tausch et al., 2011) suggested that (in particular radical) collective action can sometimes represent a 'nothing-to-lose' strategy aimed to unsettle a system that is currently unresponsive to attempts for social change. Alternatively, however, one can also argue that that the negative relationship might represent individuals' tendency to 'free ride' when there is an effective movement (Olson, 1968; see also van Zomeren et al., 2013). The inclusion of moral obligation as a proximal predictor of action in the present study allowed us to shed some light on this issue. Our findings suggest that, over and above the other predictors, a greater belief in the political effectiveness of protests might reduce personal pressure to get involved.

Our findings regarding the role of perceived risks as a predictor of intended future engagement give a number of insights into the micro-level processes that may be involved in the effects of repression on protest. As expected and in line with a deterrent effect, perceived risks predicted fear in relation to protesting, which in turn negatively predicted future action intentions. However, expected sanctions also positively predicted outrage, politicized identification, and participative efficacy, each of which were positive predictors of action intentions, directly as well as indirectly via a sense of moral obligation. There was a significant positive total effect of perceived risks, consistent with the idea that repression can galvanize protest behavior (Opp \& Roehl, 1999).

\section{Study 2: Ukraine}

The second context we examined was Ukraine. The country witnessed profound social-political changes in 2014, including the Euromaidan protests and Russia's annexation of Crimea earlier that year to the election of the pro-EU President Petro Poroshenko, who came to power with 54 percent of the electoral vote, promising to introduce radical reforms and end the war with the separatists. Although the Euromaidan social movement was still 
salient, its focus had shifted from promoting EU integration to securing Ukraine's territorial integrity under the threat of Russia's military invasion (see Bebler, 2015, for an overview of events). Specifically, the Ukraine protests were against the new government's "peace plan", which included giving special status and greater autonomy to separatist-held areas of the East (United Nations, 2014).

We targeted the protests within the context of Ukraine's return to compulsory military conscription (e.g., Balmforth, 2014) and at the time when, according to NATO reports, the country had reached an intense phase of a military conflict with Russia-backed separatists in the Eastern Provinces (e.g., Demirjian \& Birnbaum, 2014; Gordon, 2014).

\section{Method}

\section{Procedure and Respondents}

We launched the online survey in August 2014. The link to the survey was disseminated through sending mass emails to personal contacts, contacting a local NGO in the southeast region of Ukraine, and posting on several Facebook pages on which the events in the South East of Ukraine were discussed. A total of 192 participants entered the survey. We deleted the data of 56 participants who either left the survey immediately before completing any measures, completed just the demographic items, filled in some measures but none of our focal variables, or completed measures for just one of the focal constructs. The final sample was formed of 136 participants ( 77 women, 59 men; $\mathrm{M}_{\mathrm{age}}=32.06, \mathrm{SD}=9.12$ ). Most participants (89.7\%) were of Ukrainian ethnic background, the majority (38.6\%) was living in Kyiv, and most (87\%) had completed higher education. The majority of participants had some level of past participation in collective action; $5.9 \%$ were protest organizers, $25 \%$ were regular protesters, $33.1 \%$ were occasional protesters, and $22.1 \%$ were active on social networks. 


\section{Measures}

Two native speaker researchers translated the survey to Ukrainian and attended to any discrepancies. We measured past involvement in protests, likelihood of risks ( 8 items, $\alpha$ $=.91$ ), outrage, fear, political efficacy ( 8 goals, e.g., "end corruption and nepotism in Ukraine", "achieve democratization in Ukraine", "defend the territorial integrity of Ukraine", $\alpha=.90)$, identity consolidation efficacy (3 goals, $\alpha=.78$ ), participative efficacy $(r=.89, p$ $<.001)$, politicized identification $(\alpha=.94)$, moral obligation $(\alpha=.96)$, and demographics using the same measures (adapted to the Ukrainian context) as in Study 1. The survey also contained a number of additional items related to the political situation, but these were not the focus of the current analysis.

Future collective action. Participants rated their willingness to engage in nonviolent protest actions on a five-point scale ranging from not at all willing (1) to extremely willing (5) (e.g., "if the situation in Ukraine does not improve, please tell us how willing you would be to engage in nonviolent protest actions (i.e., protesting, demostrating, being active on social networks) in the very near future").

\section{Results and Discussion}

Preliminary analysis. Means, standard deviations and correlations between variables are shown in Table 3 and means and standard deviations for responses to each individual item measuring perceived risks are shown in Table 4. Again, the values suggest that these risks were relevant to participants, as most values were around the midpoint and the values of being harassed or blackmailed items were significantly higher than the midpoint. There were missing values for perceived risks $(9.6 \%)$, fear (10\%), participative efficacy $(5.9 \%)$, moral obligation (13.2\%), and collective action (19.1\%). Little's (1988) global test was marginally non-significant $\left(\chi^{2}(591)=643.632, p=.066\right)$. Similar to Study 1 , further inspection showed past involvement to positively correlate with missingness for fear $(r=-.179, p<.05)$ and 
collective action $(r=-.268, p<.01)$. Hence, we considered the missing data as missing-atrandom (MAR) and employed FIML to address this issue. We note very similar pattern in results between this method and listwise deletion ${ }^{6}$.

\footnotetext{
${ }^{6}$ The sample size decreased to $N=112$ when the listwise deletion of cases with missing values was used. The overall pattern was very similar, except that participative efficacy did not predict moral obligation $(B=.15, S E=.10, p=.122,[-.041, .340])$ and had no significant indirect path to collective action through moral obligation $(.04, S E=.04, p=.187$, $[-.006, .150])$.
} 
Table 3: Means, Standard Deviations, and Zero-order Correlations (Study 2)

\begin{tabular}{|c|c|c|c|c|c|c|c|c|c|c|c|c|}
\hline & Means & SD & 1 & 2 & 3 & 4 & 5 & 6 & 7 & 8 & 9 & 10 \\
\hline 1. Likelihood of Risk & 3.12 & .83 & 1.000 & & & & & & & & & \\
\hline 2. Outrage & 3.75 & 1.10 & .09 & 1.000 & & & & & & & & \\
\hline 3. Fear & 2.03 & .90 & $.43 * *$ & -.03 & 1.000 & & & & & & & \\
\hline 4. Political Efficacy & 3.38 & .86 & -.03 & $.20 *$ & -.03 & 1.000 & & & & & & \\
\hline 5. Identity Consolidation Efficacy & 3.79 & .77 & -.02 & $.20^{*}$ & -.01 & $.54 * *$ & 1.000 & & & & & \\
\hline 6. Participative Efficacy & 3.54 & .98 & -.05 & $.32 * *$ & -.08 & $.50 * *$ & $.45^{* *}$ & 1.000 & & & & \\
\hline 7. Politicized Identification & 3.76 & .90 & -.01 & $.34 * *$ & .07 & $.49 * *$ & $.51 * *$ & $.62 * *$ & 1.000 & & & \\
\hline 8. Moral Obligation & 3.76 & 1.09 & -.01 & $.34 * *$ & -.06 & $.49 * *$ & $.45^{* *}$ & $.61 * *$ & $.75^{* *}$ & 1.000 & & \\
\hline 9. Future Collective Action & 3.94 & .95 & .01 & $.21 *$ & .10 & $.33 * *$ & $.47 * *$ & $.50 * *$ & $.66^{* *}$ & $.62 * *$ & 1.000 & \\
\hline 10. Past Involvement & 2.78 & 1.22 & .03 & $.22 *$ & .00 & $.23 * *$ & $.33 * *$ & $.46^{* *}$ & $.54 * *$ & $.56^{* *}$ & $.43 * *$ & 1.000 \\
\hline
\end{tabular}


Table 4: Means, Standard Deviations for Perceived Risks (Study 2)

\begin{tabular}{ll}
\hline \hline Perceived Risks & $M(S D)$ \\
\hline Risking employment/or university degree & $2.95(1.03)$ \\
$\begin{array}{l}\text { Being harassed by the opponent parties' representatives } \\
\text { Having a family member being harassed by the opponent parties' }\end{array}$ & $3.78(.95)$ \\
$\begin{array}{l}\text { representatives } \\
\text { "Blackmailing" by state controlling units (such as tax inspectorate of }\end{array}$ & $3.37(1.09)$ \\
personal businesses) & \\
Being imprisoned (or detained) & $3.17(1.09)$ \\
Being arrested & $2.95(1.16)$ \\
Being tortured & $2.71(1.19)$ \\
Being killed & $2.46(1.18)$ \\
\hline
\end{tabular}

Note: The items were rated on five-point scales ranging from very unlikely (1) to very likely (5)

Path analysis. Figure 3 presents results from our path analysis (see Table S3 in the Supplementary Material for a detailed report). Confirming H1, perceived risks predicted fear $(B=.46, S E=.10, p<.001,[.268, .653])$. Contrary to the hypotheses, perceived risks did not predict any of the remaining variables: outrage $(\mathrm{H} 2 ; B=.07, S E=.13, p=.565$, $[-.179, .313])$, political efficacy $(\mathrm{H} 3 \mathrm{a} / \mathrm{b} ; B=-.04, S E=.10, p=.719,[-.234, .151])$, identity consolidation efficacy $(\mathrm{H} 4 \mathrm{a} / \mathrm{b} ; B=-.03, S E=.07, p=.638,[-.173, .105])$, participative efficacy $(\mathrm{H} 5 \mathrm{a} / \mathrm{b} ; B=-.08, S E=.09, p=.358,[-.265, .102])$, politicized identification (H6; $B$ $=-.02, S E=.09, p=.827,[-.196, .153])$.

In line with hypotheses $\mathrm{H} 7$ and $\mathrm{H} 8$, politicized identification $(B=.55, S E=.11, p$ $<.001,[.309, .759])$ and participative efficacy $(B=.18, S E=.09, p=.037,[.002, .351])$ positively predicted moral obligation, but identity consolidation efficacy, political efficacy, and outrage did not $(\mathrm{H} 9, B=.02, S E=.09, p=.840,[-.166, .184], \mathrm{H} 10, B=.14, S E=.09, p$ $=.116,[-.031, .315])$, and H11, $B=.06, S E=.06, p=.300,[-.054, .172])$ respectively).

Consistent with Study 1, politicized identification $(B=.30, S E=.13, p=.027$, $[.018, .543])$ and moral obligation $(\mathrm{H} 13, B=.28, S E=.13, p=.031,[.045, .538])$ positively predicted action intentions. Contrary to $\mathrm{H} 12$, fear $(B=.07, S E=.08, p=.370,[-.086, .220])$ did not predict action intentions. Outrage $(B=.01, S E=.07, p=.848,[-.112, .152])$, political 
efficacy $(B=-.06, S E=.10, p=.548,[-.271, .132])$, identity consolidation efficacy $(B=.14$, $S E=.11, p=.213,[-.080, .364])$, and participative efficacy $(B=.11, S E=.09, p=.232$, $[-.068, .290])$ were also not significant predictors. The model explained $46 \%$ of the variance in collective action intentions.

Unlike in Study 1, there was no significant indirect path from perceived risks to collective action $(.00, S E=.07, p=.967,[-.124, .154])$. The total path from perceived risks to collective action was also non-significant $(-.10, S E=.08, p=.246,[-.257, .070])$.

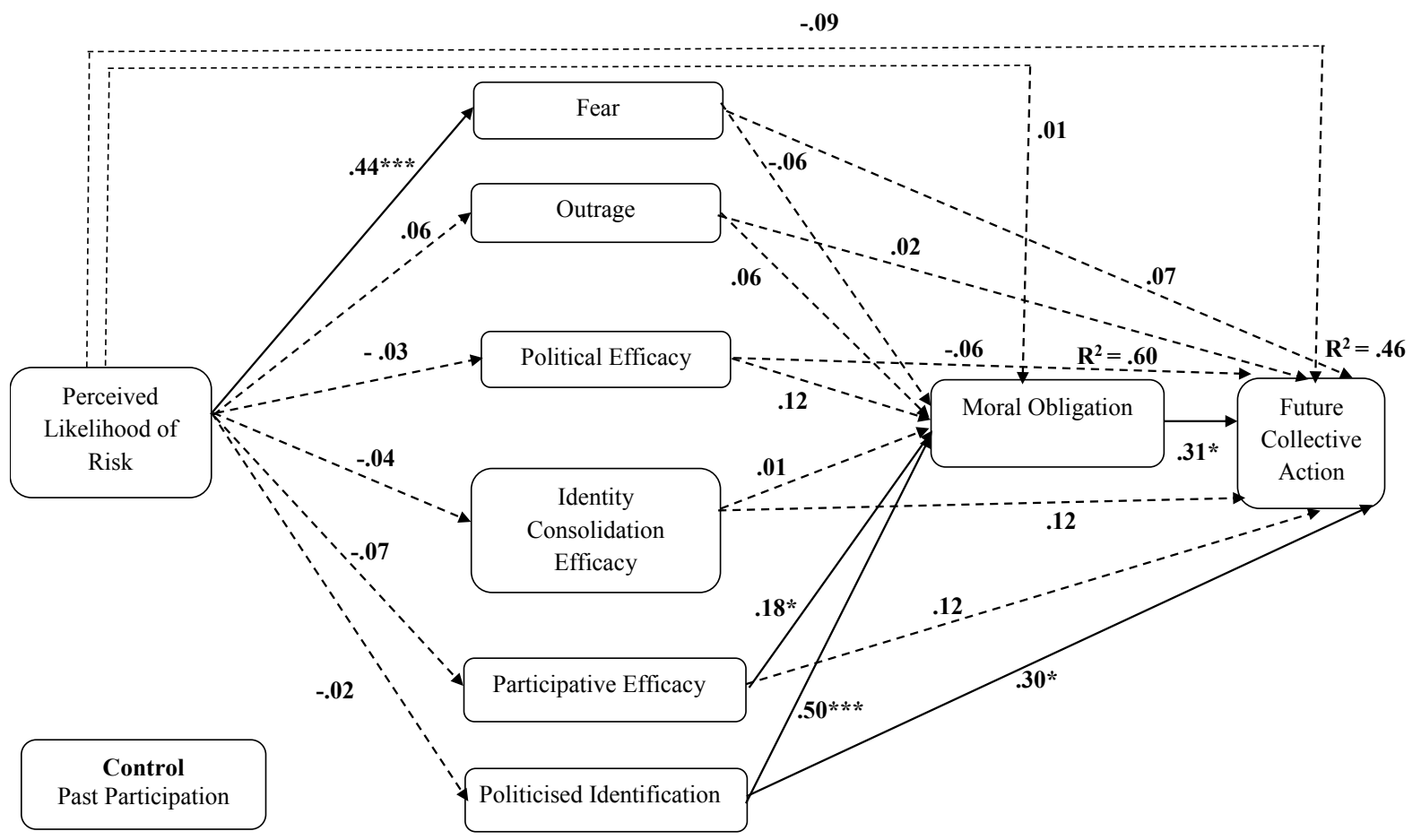

Figure 3: Results of path analysis in the Ukrainian sample (Study 3, $N=136$ ). The dashed arrows are the non-significant paths. The coefficients are the standardized regression estimates. ${ }^{*} p<.05, * * p<.01, * * * p<.001$. Past involvement in protests was considered as covariate. It positively predicted outrage $(\beta=.23 * *)$, political efficacy $(\beta=.23 * *)$, identity consolidation efficacy $(\beta=.32 * *)$, participative efficacy $\left(\beta=.48^{* * *}\right)$, politicized identification $\left(\beta=.55^{* * *}\right)$, and moral obligation $\left(\beta=.20^{* *}\right)$.

As in Study 1 and in line with previous research (Stürmer et al., 2003), the present results confirmed the importance of politicized identification and moral obligation as the 
preeminent predictors of future action intentions. However, emotions and efficacy beliefs did not have any predictive roles in this particular context. Concerning the role of perceived risks as a distal predictor of action intentions, results only confirmed the inhibitory role of perceived risks through increasing feelings of fear experienced due to repression of protest, as all other paths from perceived risks to collective action antecedents and action intentions were not significant. Finally, only politicized identification and participative efficacy positively predicted moral obligation. Their paths to action intentions were partially mediated by moral obligation, partly affirming the importance of moral obligation as a proximal predictor of action intentions.

The results from Ukraine differed from the previous study, as most of the hypotheses relating to perceived risks were not supported. Moreover, most constructs did not predict moral obligation, and the model explained a lower percentage of variance in collective action. These results might be due to the period during which the survey was conducted. We launched the survey when several protests were organized to voice disapproval of the Russian separatists and the Ukrainian government's handling of the military operation in the southeast of Ukraine (Gordon, 2014). Since Ukraine was at the edge of war with Russia, it is possible that the risks associated with these protests might have been less relevant to our respondents compared to the risks and costs of war.

In sum, results from Study 2, consistent with Study 1, confirmed political efficacy to be a trivial motivator and politicized identification and moral obligation to be the prime motivators of collective action intentions in high-risk context. These consistent findings suggest that in such contexts, protesters' drive to resist despite the considerable risks they face is not the potential political or social benefits but their identification with the resistance movement and sense of duty to take action. 


\section{Study 3: Hong Kong}

Since 1997, Hong Kong has been a Special Administrative Region of China.

Although China aknowledged the autonomy of Hong Kong according to the initial agreement between the two countries, China has recurrently overruled this agreement (BBC news, 2015; McKirdy, 2014; Ortman, 2015; Tweed, 2016). One aspect of the Chinese government's interference relates to the Hong Kong electoral laws. In 2007, the Chinese government promised Hong Kong to allow its citizens to directly elect their Chief Executive officer in 2017 and their legislators by 2020. However, in 2012, the new laws of legistlative elections disregarded these promises and maintained the old electoral system (see Chan, 2014, for a review of the electoral system). Consequently, three professors at the University of Hong Kong inititated the Occupy Central with Love and Peace movement, which promoted civil disobedience to advocate for the democratization of electoral procedures (Chan, 2014; Ortmann, 2015). At the end of August 2014, following the announcement that the electoral system for the 2017 elections would remain unchanged, a number of student organizations began boycotting classes, and Occupy Central organized protests and staged sit-ins to voice their disapproval of this decision and call for electoral reform (Chan, 2014; Ortman, 2015). Along with their main demand of open and popular voting for Hong Kong's chief executive in 2017, protesters called for the chief executive officer to step down and democracy in general to be respected (Chan, 2014). Throughout the protesting period, the police vastly and indiscriminately used teargas, pepper spray, batons, and physical force to clear the protest sites, and the government responded with increases in censorship, court orders, and arrests (Barber, 2014; Branigan, 2014; Lague, Torode, \& Pmfret, 2014; Tsui, 2015). In response to the police actions, the protesters used umbrellas as a form of defense and the movement was therefore coined as the Umbrella Movement (Henley, 2014). The protests and sit-ins lasted until December, when a gradual clearing of the protest sites started. 


\section{Method}

\section{Procedure and Respondents}

The online survey began in November 2014, while the protests were still ongoing. The link to the survey was posted on several Facebook pages promoting the Umbrella Movement, tweeted, and emailed to personal contacts in Hong Kong (e.g., friends, academics, and activists). A total of 166 participants entered the survey. We deleted the data of 55 participants who either immediately left the survey after reading the informed consent, answered only the demographics information and some preliminary items, or filled in two of the focal constructs, which left a sample of 115 participants (52 women, 60 men, 3 preferred not to answer; $\left.M_{\mathrm{age}}=29.37, S D=9.41\right)$. Most participants were from Hong Kong $(86.7 \%)$ and of Chinese ethnic background (77.4\%) and most (51.4\%) had an undergraduate degree (31.4\% had higher education). The majority of the participants had some level of past participation in collective action; $19.3 \%$ were regular protesters, $52.3 \%$ were occasional protesters, and $15.6 \%$ were active on social networks.

\section{Measures}

The survey was translated to Chinese by one of the authors, who is a native speaker. We measured past involvement in protests, likelihood of risk ( 8 items, $\alpha=.91$ ), emotions (i.e., outrage, fear), political efficacy (2 goals, i.e., "protect democracy in Hong Kong" and "respect the freedom of speech and other democratic freedoms", $r=.84, p<.001$ ), identity consolidation efficacy ( 2 goals, i.e., "strengthen the solidarity among the protesters", "helping in building a mass movement in Hong Kong for democratic freedoms in Hong Kong", $r$ $=.69, p<.001)$, participative efficacy $(r=.85, p<.001)$, politicized identification $(\alpha=.95)$, moral obligation $(\alpha=.95)$, future collective action, and demographics using the same measures (adapted to the Hong Kong context) as in Studies 1 and 2. Although additional 
items related to the political context were included, these were not part of the present analysis.

\section{Results and Discussion}

Preliminary analyses. Means, standard deviations and correlations between the model variables are presented in Table 5 and means and standard deviations for responses to each individual item related to perceived risks are shown in Table 6. Participants scored significantly higher than the midpoint on all items, suggesting that being victims of these risks was perceived to be highly possible. Only past participation (7\%), moral obligation (10.4\%), and collective action (9.6\%) had missing values of more than 5\%. Little's (1988) global test was not significant, indicating that the overall missing data pattern is completely at random $\left(\right.$ MCAR, $\left.\chi^{2}(442)=462.574, p=.241\right)$. As in Study 1 and 2, we used FIML to address the missing values issue and we noted small differences between this method and listwise deletion ${ }^{7}$.

Path analysis. We summarize the results in Figure 4 and report the detailed analysis in Table S5 in the Supplementary Material. As hypothesized, perceived risks positively predicted outrage $(\mathrm{H} 1, B=.50, S E=.13, p<.001,[.221, .729])$, fear $(\mathrm{H} 2, B=.72, S E=.12$, $p<.001,[.477, .945])$ and political efficacy $(\mathrm{H} 3 \mathrm{~b}, B=.29, S E=.14, p=.046,[.011, .565])$,

\footnotetext{
${ }^{7}$ The sample size was reduced to $N=97$ when we used the listwise deletion method. Only a few differences were noted in the results. Politicized identification did not predict collective action $(B=.24, S E=.13, p=.069,[-.019, .502])$ and was not a mediator between perceived risks and collective action $(.12, S E=.08, p=.089,[-.010, .319])$. However, perceived risks predicted moral obligation $(B=.52, S E=.11, p<.001,[.318, .726])$ and indirectly predicted action intentions through moral obligation $(.16, S E=.08, p=.030,[.039, .370])$. Participative efficacy did not predict moral obligation $(N=99, B=.17, S E=.10, p=.075,[-.017, .361])$.
} 
identity consolidation efficacy $(\mathrm{H} 4 \mathrm{~b}, B=.41, S E=.13, p=.001,[.152, .654])$, participative efficacy (H5b, $B=.54, S E=.11, p<.001$, [.283, .729]), and politicized identification (H6, $B$ $=.47, S E=.11, p<.001,[.242, .660])$.

Also as expected ( $\mathrm{H} 7, \mathrm{H} 8, \mathrm{H} 9$, and $\mathrm{H} 11$, respectively), politicized identification ( $B$ $=.28, S E=.10, p=.006,[.081, .471])$, participative efficacy $(B=.24, S E=.09, p=.009$, $[.044, .410])$, identity consolidation efficacy $(B=.24, S E=.08, p=.005,[.073, .399])$, and outrage $(B=.27, S E=.06, p<.001,[.157, .388])$ positively predicted moral obligation. However, contrary to $\mathrm{H} 10 \mathrm{a} / \mathrm{b}$, political efficacy $(B=-.08, S E=.07, p=.266,[-.214, .065])$ did not predict moral obligation.

Politicized identification $(B=.31, S E=.13, p=.019,[.062, .582])$ and moral obligation $(\mathrm{H} 13 ; B=.29, S E=.11, p=.011,[.086, .531])$ positively predicted collective action intentions. Contrary to H12, fear $(B=-.04, S E=.06, p=.477,[-.153, .071])$ did not predict collective action. The model explained $63 \%$ of the variance in collective action intentions. 
Table 5: Means, Standard Deviations, and Zero-order Correlations (Study 3)

\begin{tabular}{|c|c|c|c|c|c|c|c|c|c|c|c|c|}
\hline & Mean & SD & 1 & 2 & 3 & 4 & 5 & 6 & 7 & 8 & 9 & 10 \\
\hline 1. Likelihood of Risk & 3.77 & .86 & 1.000 & & & & & & & & & \\
\hline 2. Outrage & 4.33 & 1.13 & $.53^{* *}$ & 1.000 & & & & & & & & \\
\hline 3. Fear & 2.76 & 1.29 & $.43 * *$ & $.33 * *$ & 1.000 & & & & & & & \\
\hline 4. Political Efficacy & 3.46 & 1.07 & $.26^{*}$ & $.23 *$ & .01 & 1.000 & & & & & & \\
\hline 5. Identity Consolidation Efficacy & 3.98 & .91 & $.44^{* *}$ & $.49^{* *}$ & $.22 *$ & $.57^{* *}$ & 1.000 & & & & & \\
\hline 6. Participative Efficacy & 3.62 & 1.08 & $.54 * *$ & $.61^{* *}$ & $.24^{*}$ & $.51 * *$ & $.66^{* *}$ & 1.000 & & & & \\
\hline 7. Politicized Identification & 3.73 & 1.02 & $.56^{* *}$ & $.68^{* *}$ & $.33 * *$ & $.40 * *$ & $.59^{* *}$ & $.78^{* *}$ & 1.000 & & & \\
\hline 8. Moral Obligation & 4.11 & 1.03 & $.60 * *$ & $.74 * *$ & $.33 * *$ & $.26^{* *}$ & $.58 * *$ & $.71 * *$ & $.75^{* *}$ & 1.000 & & \\
\hline 9. Future Collective Action & 4.32 & 1.10 & $.47^{* *}$ & $.67 * *$ & $.22 * *$ & $.34^{* *}$ & $.56^{* *}$ & $.67 * *$ & $.73 * *$ & $.71^{* *}$ & 1.000 & \\
\hline 10. Past Involvement & 2.70 & 1.02 & $.46^{*}$ & $.52 * *$ & .07 & .17 & $.31 * *$ & $.48^{* *}$ & $.56^{* *}$ & $.51 * *$ & $.54 * *$ & 1.000 \\
\hline
\end{tabular}


Table 6: Means, Standard Deviations for Perceived Risks (Study 3)

\begin{tabular}{ll}
\hline Perceived Risks & $M(S D)$ \\
\hline Risking employment/expel from university & $3.53(1.09)$ \\
Being harassed by the police & $4.08(1.12)$ \\
Being harassed by the gangsters & $4.22(1.04)$ \\
Having a family member harassed by the police & $3.34(1.18)$ \\
Having a family member harassed by the gangsters & $3.50(1.16)$ \\
Being arrested & $4.23(.91)$ \\
Being imprisoned, detained for some time & $3.86(1.02)$ \\
Being tortured & $3.37(1.27)$ \\
\hline Note:
\end{tabular}

Note: The items were rated on five-point scales ranging from very unlikely (1) to very likely (5)

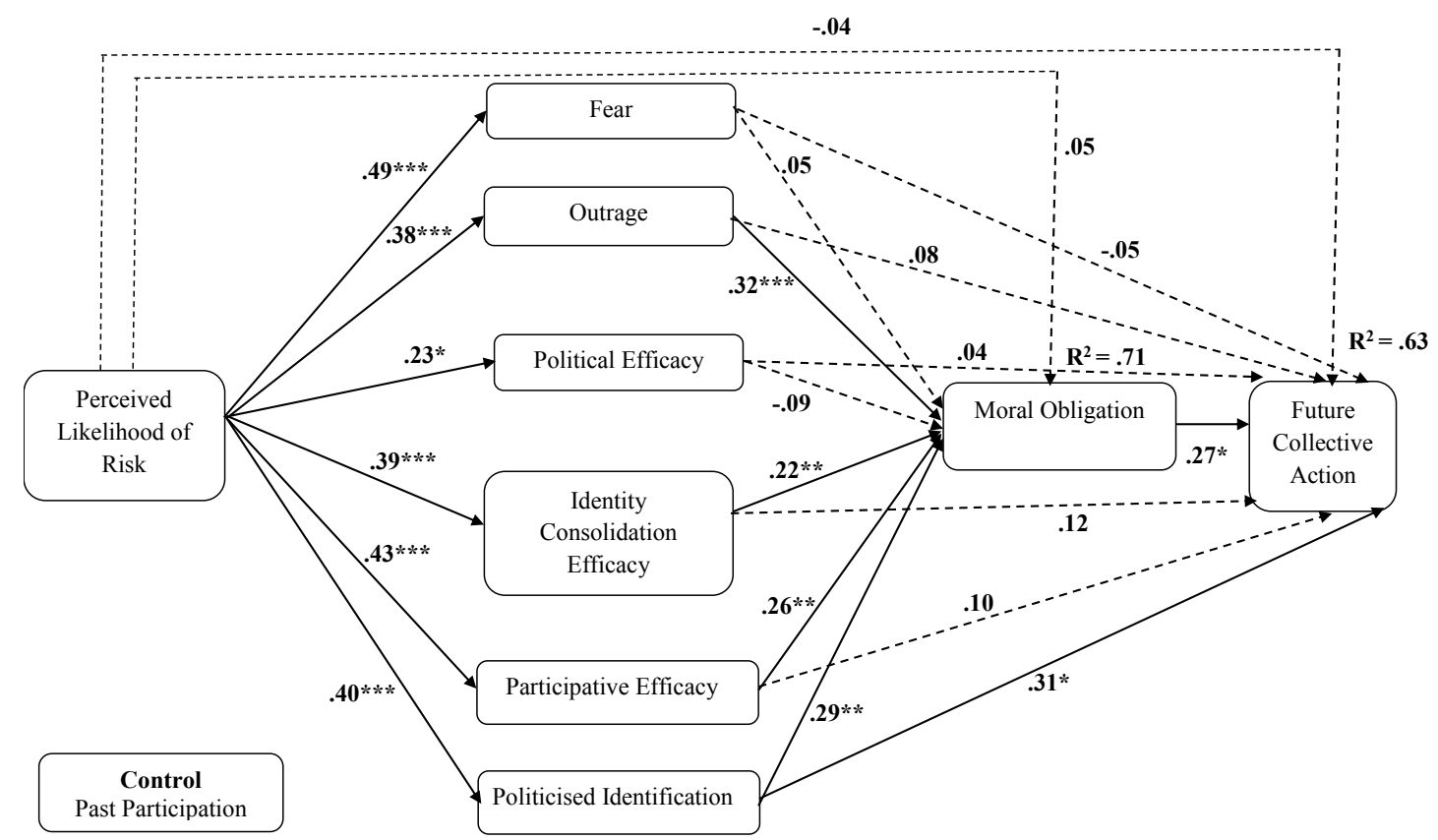

Figure 4: Results of path analysis in the Hong Kong sample (Study 1, $N=115$ ). The dashed arrows are the non-significant paths. The coefficients are the standardized regression estimates. ${ }^{*} \mathrm{p}<.05, * * \mathrm{p}<.01, * * * \mathrm{p}<.001$. Past involvement in protests was considered as a covariate. It positively predicted outrage $\left(\beta=.34^{* * *}\right)$, participative efficacy $\left(\beta=.26^{* *}\right)$, and politicized identification $(\beta=.37 * * *)$.

Importantly, and consistent with the idea that risks imposed by the authorities can incite further resistance, there was a significant positive total path from perceived risks to action intentions $(.39, S E=.15, p=.008,[.071, .648])$ and perceived risks indirectly 
predicted action intentions through politicized identification $(.15, S E=.07, p=.045$, $[.033, .337])$

In sum, our findings yet again confirm politicized identification to be the strongest predictor of collective action in repressive contexts, and, in line with previous research (Stürmer et al., 2003; Vilas et al., 2012), that its effect is partially mediated by moral obligation. Our results closely reverberate Tsung-an's (2017) detailed personal account of the protests where she considered the formation of a community, based on a shared identity, trust, solidarity, cooperation and personal initiatives, to be the nucleus of the movement. Consistent with the idea that repression can galvanize resistance, perceived risks positively predicted outrage, the three facets of perceived efficacy and politicized identification and had a total positive effect on action intentions through politicized identification. These results are again in line with the backfire effect of authority sanctions and delineate the specific "micromobilization" processes that underlie resistance in the face of repression (Opp \& Roehl, 1990, p. 523). In particular, the positive link between perceived risks and political efficacy resonates with Tsung-gang's (2017) description of the events, which suggested that protesters perceived the violent repression as a sign of the authorities' weakness in withstanding the protests. Similarly, our finding of moral obligation as an important motivator of action complements Tsung-gan's (2017) elaboration on the paramount importance of protesters' "general feeling that something had to be done" (p. 381) and their personal sense of responsibility.

\section{Study 4: Turkey}

Turkey witnessed a wave of recent protests that started in May 2013. The initial protest movement had the aim to prevent the destruction of Gezi Park in Istanbul and the construction of a shopping mall (Bilgin, 2013). By May $31^{\text {st }} 2013$, the environmentally oriented protests changed into political protests against Prime Minister Recep Tayyip 
Erdoğan's perceived authoritarian and anti-democratic rule once the police violently repressed the peaceful protests in an attempt to evict the protesters from the park (Gokay \& Shain, 2013; Morris, 2013). The protests in Gezi Park were forcibly evicted from the park on June $25^{\text {th }} 2013$; however, numerous protests still took place against the government-led urbanization and regeneration projects across the country (e.g., Hevsel, Yrrca, Sulukule, and Okmeydan1). These projects were developed with no consultation with the local residents nor environmental considerations or monitoring. The government also amended the laws to facilitate these projects and used force to suppress any attempted resistance (Pierini, 2013).

During Gezi and related protests, the police repeatedly used water cannons, tear gas, and rubber bullets to disperse the protesters; hundreds of protesters were arrested, thousands injured, and eleven killed (Alexander, 2013; Amnesty International, 2015). Moreover, the government suppressed the press, freedom of assembly and freedom of expression, and controlled the judicial system (e.g., unfair trials of anyone questioning authorities' rule) (Harrington, 2015). On March 25 $5^{\text {th }} 2015$, new reforms gave the police wider powers to repress resistance through detentions and the use of firearms (Amnesty International, 2015).

\section{Method}

\section{Procedure and Respondents}

On May 22, 2015, we launched an online survey at Özyeğin University in Istanbul. The link to the survey was sent to students taking psychology classes ${ }^{8}$. A total of 316

\footnotetext{
${ }^{8}$ We designed the study as an experiment where we manipulated the likelihood of risks (high vs. low). To ensure a greater variability in the participants' past protests involvement, hence, a greater likelihood of them believing the manipulation, we targeted students. However, there was no significant difference in perceived risks between conditions $(t(294)=.484, p=.628)$.
} 
participants entered the survey. After deleting the data of 20 participants who either left the survey immediately after the informed consent or before completing any measures, or completed some measures but none of our focal variables, the final sample was composed of 296 participants (178 women, 116 men, and 3 preferred not to answer; $M_{\mathrm{age}}=21.86, S D=$ 1.761). Most participants (35.8\%) were psychology major students and the majority $(89.5 \%)$ were of Turkish ethnic background. The majority had some level of past participation in collective action; $0.4 \%$ were protest organizers, $4.1 \%$ were regular protesters, $21.9 \%$ were occasional protesters, and $27.8 \%$ were active on social networks.

\section{Measures}

One of the authors, a native speaker, translated the survey to Turkish. We measured past involvement in protests, likelihood of risks ( 7 items, $\alpha=.87$ ), political efficacy ( 2 goals, e.g., "stop further unwanted urbanization across the country", "prevent further building in green spaces in Istanbul", $r=.66, p<.001$ ), identity consolidation efficacy (2 goals, $r=.61$, $p<.001)$, participative efficacy $(r=.53, p<.001)$, politicized identification $(\alpha=.90)$, and moral obligation $(\alpha=.91)$ using the same measures as in the previous study but adapted to the Turkish context. Although other items related to the political context were also included, these were not part of the present analysis. Along with past involvement in protests, gender (1 $=$ Male, $2=$ Female ) was included as a control variable as it significantly correlated with the model variables.

Emotions. On a five-point scale ranging from not at all (1) to a great extent (5), participants evaluated how outraged and fearful they were of Turkish police's treatment of protesters (e.g., "When thinking about how the Turkish police is likely to treat the protesters,

Consequently, we decided to use the data as a survey data, while controlling for experimental condition $(1=$ low risks, $2=$ high risks $)$. 
to what extent do you feel: 1) afraid of the consequences for protesters 2) outraged about the police's behavior").

Future collective action. Participants rated their willingness to engage in six peaceful collective actions as part of the upcoming protests against the government-led urban regeneration projects in Turkey using a five-point scale ranging from not at all willing (1) to extremely willing (5) (e.g., "demonstrate peacefully", "participate in marches", "participate in strikes", "sign petitions", "express disapproal of urbanization on social networks", and "participate in sit-ins"; $\alpha=.89$ ).

\section{Results and Discussion}

Preliminary analyses. We present the means, standard deviations and Pearson correlations between the variables in Table 7 and the means and standard deviations for responses to each individual item related to perceived risks in Table 8 . The means on all the items were significantly higher than the midpoint, and some items almost approached the highest score of 5 (i.e., being injured and detained), suggesting these risks were highly relevant to our participants during this particular period. Outrage, fear, likelihood of risk, as well as political and identity consolidation efficacies had less than $5 \%$ of missing values. The remaining variables had missing values ranging between 5.7 and 15.5\%. Little MCAR test was significant, $\chi^{2}(2006)=2302.979, p<.001$, indicating that the overall distribution of missing data is not completely at random.

We inspected whether there are any consistent patterns in the relations between missingness on single variables and the available data. Past participation positively correlated with missingness for fear $(r=.125, p<.05)$, perceived risks $(r=.162, p<.01)$ and political efficacy $(r=.162, p<.01)$, suggesting that those who were politically more active were more likely to have missing values on these variables, possibly due to their fear of being monitored. Moreover, past participation negatively correlated with missingness for 
participative efficacy $(r=-.145, p<.01)$ suggesting, as argued previously, participants with lower levels of involvement in protests to be less likely to answer some of the questions related directly to activism. Given these systematic relationships between the main constructs and missing values, we concluded the pattern of missing values to be at random (MAR), used FIML to address the issue of missing values, and reported the differences between this method and listwise deletion ${ }^{9}$.

\footnotetext{
${ }^{9}$ The sample size was reduced to $N=229$ when we used the listwise deletion method. Only two differences were noted in the results; the direct path from fear to collective action only approached significance $(B=.16, S E=.08, p=.054,[-.003, .325])$ and fear emerged as a predictor of moral obligation $(B=.17, S E=.08, p=.033,[.014, .320])$.
} 
Table 7: Means, Standard Deviations, and Zero-order Correlations (Study 4)

\begin{tabular}{|c|c|c|c|c|c|c|c|c|c|c|c|c|c|}
\hline & Means & SD & 1 & 2 & 3 & 4 & 5 & 6 & 7 & 8 & 9 & 10 & 11 \\
\hline 1. Likelihood of Risk & 3.96 & .73 & 1.000 & & & & & & & & & & \\
\hline 2. Outrage & 4.22 & 1.18 & $.44^{* *}$ & 1.000 & & & & & & & & & \\
\hline 3. Fear & 4.38 & .98 & $.54 * *$ & $.67 * *$ & 1.000 & & & & & & & & \\
\hline 4. Political Efficacy & 2.31 & .86 & .00 & -.02 & -.01 & 1.000 & & & & & & & \\
\hline 5. Identity Consolidation Efficacy & 3.36 & .75 & $.25^{* *}$ & $.23 * *$ & $.39 * *$ & $.43 * *$ & 1.000 & & & & & & \\
\hline 6. Participative Efficacy & 2.91 & .98 & $.13^{* *}$ & $.17 * *$ & $.16^{* *}$ & $.14^{*}$ & $.23 * *$ & 1.000 & & & & & \\
\hline 7. Politicized Identification & 3.35 & .88 & $.31 * *$ & $.37 * *$ & $.45^{* *}$ & .02 & $.29 * *$ & $.27 * *$ & 1.000 & & & & \\
\hline 8. Moral Obligation & 3.22 & 1.00 & $.42 * *$ & $.43 * *$ & $.50 * *$ & .10 & $.32 * *$ & $.28 * *$ & $.59 * *$ & 1.000 & & & \\
\hline 9. Future Collective Action & 3.43 & 1.01 & $.46^{* *}$ & $.51 * *$ & $.58 * *$ & $.16^{* *}$ & $.42 * *$ & $.27 * *$ & $.58 * *$ & $.64 * *$ & 1.000 & & \\
\hline 10. Past Involvement & 2.00 & 1.15 & $.23 * *$ & $.28 * *$ & $.29 *$ & $.17 * *$ & $.23 * *$ & $.14^{*}$ & $.31 * *$ & $.44 * *$ & $.42 * *$ & 1.000 & \\
\hline 11. Gender (1 Male, 2 Female) & - & - & $.23 * *$ & $.19 * *$ & $.30 * *$ & -.04 & $.21 * *$ & .12 & $.31 * *$ & $.33 * *$ & $.35 * *$ & $.19 * *$ & 1.000 \\
\hline
\end{tabular}


Table 8: Means, Standard Deviations for Perceived Risks (Study 4)

\begin{tabular}{ll}
\hline \hline Perceived Risks & $M(S D)$ \\
\hline Risking being expelled from university & $3.43(1.08)$ \\
Phones tapped by the police & $4.06(.96)$ \\
Being injured & $4.45(.77)$ \\
Being arrested & $4.35(.81)$ \\
Being detained for sometime & $4.39(.81)$ \\
Being imprisoned & $3.67(1.03)$ \\
Being killed & $3.34(1.20)$ \\
\hline Note: The items were rated on five-point scales ranging from very unlikely $(1)$ to very likely
\end{tabular}
(5)

Path analysis. We summarize the results in Figure 5 and report the detailed analysis in Table S7 in the Supplementary Material. As hypothesized, perceived risks positively predicted outrage $(\mathrm{H} 1 ; B=.62, S E=.08, p<.001,[.451 .771])$, fear $(\mathrm{H} 2 ; B=.64, S E=.07, p$ $<.001,[.503, .767])$, identity consolidation efficacy $(\mathrm{H} 4 \mathrm{~b} ; B=.30, S E=.07, p<.001$, $[.164, .433])$, and politicized identification $(\mathrm{H} 6 ; B=.26, S E=.06, p<.001,[.142, .381])$. Perceived risks did not, however, predict political efficacy $(\mathrm{H} 3 \mathrm{a} / \mathrm{b} ; B=-.03, S E=.08, p$ $=.663,[-.186, .120])$ or participative efficacy $(\mathrm{H} 5 ; B=.12, S E=.07, p=.105,[-.022, .267])$.

Confirming hypotheses $\mathrm{H} 7$ and $\mathrm{H} 8$, politicized identification $(B=.42, S E=.08, p$ $<.001,[.284, .575])$ and participative efficacy $(B=.10, S E=.04, p=.030,[.007, .180])$ positively predicted moral obligation. However, contrary to our hypotheses, identity consolidation efficacy $(\mathrm{H} 9 ; B=.03, S E=.05, p=.518,[-.065, .143])$, political efficacy $(\mathrm{H} 10 \mathrm{a} / \mathrm{b} ; B=.04, S E=.06, p=.461,[-.071, .153])$, and outrage $(\mathrm{H} 11 ; B=.05, S E=.04, p$ $=.238,[-.029, .150])$ did not predict moral obligation.

Outrage $(B=.11, S E=.05, p=.025,[.016, .213])$, identity consolidation efficacy $(B$ $=.18, S E=.06, p=.002,[.058, .293])$, politicized identification $(B=.28, S E=.07, p<.001$, $[.143, .428])$, and moral obligation $(\mathrm{H} 13 ; B=.24, S E=.06, p<.001,[.124, .363])$ positively predicted collective action intentions. Contrary to expectations, fear $(\mathrm{H} 12 ; B=.12, S E=.05$, $p=.049,[.002, .242])$ positively predicted action intentions and had an indirect positive path 
to willingness to engage in collective action through moral obligation $(.03, S E=.02, p$ $=.090,[.001, .066])$. Political efficacy $(B=.09, S E=.05, p=.081,[-.008, .208])$ and participative efficacy $(B=.02, S E=.05, p=.587,[-.067, .116])$ did not predict action intentions. Perceived risks $(B=.12, S E=.07, p=.060,[-.021, .254])$ had no direct link to collective action. The model explained $58 \%$ of the variance in participants' action intentions.

Perceived risks indirectly predicted collective action $(.38, S E=.06, \mathrm{p}<.001$, $[.263, .498])$ specifically through fear $(.08, S E=.04, p=.050,[.003, .156])$, outrage $(.07, S E$ $=.03, p=.038,[.011, .144])$, identity consolidation efficacy $(.06, S E=.02, p=.012$, $[.018, .104])$, politicized identification $(.07, S E=.03, p=.009,[.029, .141])$, and moral obligation $(.04, S E=.02, p=.017,[.017, .095])$. The total path from perceived risks to collective action was positive and significant $(.50, S E=.07, p<.001,[.352, .642])$.

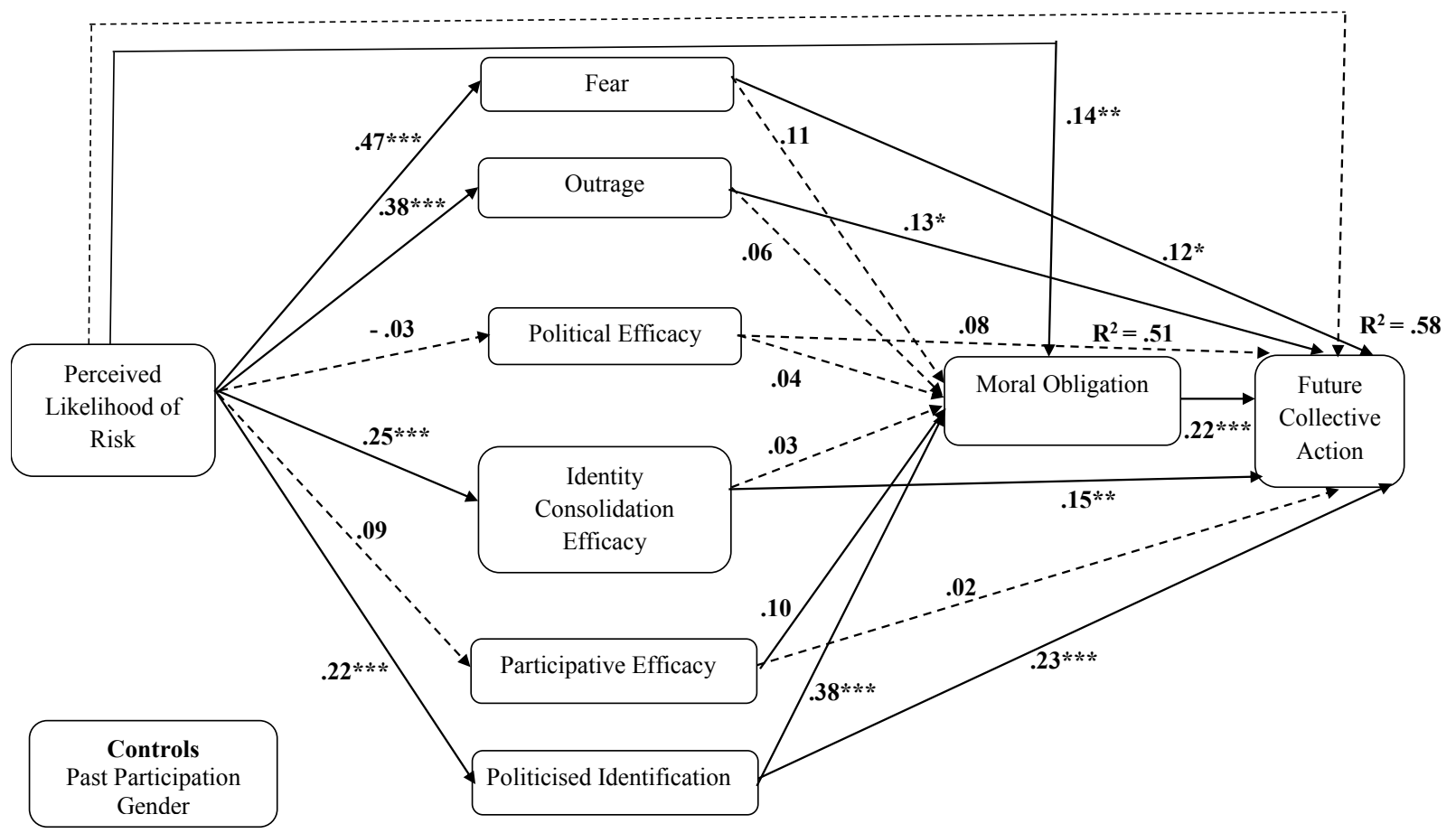

Figure 5: Results of path analysis in the Turkish sample (Study 4, $N=296$ ). The dashed arrows are the non-significant paths. The coefficients are the standardized regression estimates. $* \mathrm{p}<.05, * * \mathrm{p}<.01, * * * \mathrm{p}<.001$. Past involvement in protests and gender were considered as covariates. Past involvement positively predicted fear $(\beta=.14 * * *)$, outrage $(\beta$ $\left.=.18^{* * *}\right)$, political efficacy $\left(\beta=.20^{* * *}\right)$, politicized identification $(\beta=.24 * * *)$, moral obligation $\left(\beta=.21^{* * *}\right)$, and collective action $\left(\beta=.13^{* *}\right)$. Gender predicted fear $\left(\beta=.16^{* *}\right)$, 
identity consolidation efficacy $\left(\beta=.17^{* *}\right)$, and politicized identification $\left(\beta=.21^{* * *}\right)$. The manipulation did not predict any of the variables.

Overall, these findings further confirm most of our hypotheses (i.e., backlash effect through outrage, the role of participative efficacy as a predictor over and above the 'traditional' predictors of collective action), and highlight the importance of politicized identification as the strongest predictor of collective action intentions in high-risk contexts. Contrary to hypothesis $\mathrm{H} 12$, however, fear positively predicted collective action intentions. A possible explanation for this positive link could be that in contexts where civil resistance is strongly repressed, a reality reflected in the mean of perception of risks and the individual item of "being killed", people often also act out of fear in an attempt to avert threats, particularly if they believe that not acting can make the situation worse. Particular to the Turkish context, participants might been afraid of Turkey becoming an authoritarian regime. Hence, fear of such repressive developments in the country, rather than only outrage towards authorities, might have encouraged some to get engaged.

We refer to the particular Turkish context to explain the non-significance of political efficacy to predict collective action. During the 2013 and more recent protests, the protesters were harshly repressed, imprisoned, and even killed. Recent laws expanded police authority to use force against the protesters. As no significant changes to the political system were implemented after the protests (Böcü, 2015), protesters' belief that the protests can make a difference might not be strong enough to motivate them to take action under considerable risks. However, the likelihood of achieving a strengthened opposition movement, identification with the protest movement, and one's sense of moral responsibility to take action significantly predicted willingness to engage in collective action. These results resonate with Letsch's (2014) report of the Gezi Park protests. 


\section{Meta-Analysis}

To integrate the results from the four studies more formally and strengthen our conclusions, we tested our proposed model meta-analytically (Goh, Hall, \& Rosenthal, 2016). Since the parameter estimates were not independent (i.e., several parameters are estimated per study), we could not follow the univariate meta-analysis techniques. Hence, we used the meta-analytic structural equation modeling (MASEM), which is a multivariate method of meta-analyzing data whereby the dependence among the different correlation matrices is accounted for (Cheung, 2015a, 2015b). Specifically, MASEM integrates two statistical analyses; structural equation modeling and meta-analysis (Cheung \& Cheung, 2014; Cheung \& Hafdahl, 2016). It allows researchers to test a specific model, and the significance of direct and indirect effects across the different samples. In the correlation-based MASEM, the correlation matrices from different studies are synthesized, and the specific model under study is fitted to the merged correlation matrix (Cheung, 2015a, 2015b).

We conducted MASEM using the R software and a code developed by Cheung (2015a, 2015b). We used the fixed-effect model since the primary purpose here was to provide a summary of the results and not infer the distribution of the effect sizes, nor to attempt to generalize the results beyond the four present studies (Hedges \& Vevea, 1998). The fixed-effects in MASEM, based on weighted least squares estimation, is similar to the fixed-effects meta-analysis based on generalized least squares estimation. We followed the WLS estimation method since the distribution of the data is not normal. We examined the 95\% Likelihood Based Intervals for significance and report the standardized coefficients. These procedures ensure the validity of the estimates since they are unbiased (e.g., independent of the sample sizes of each study; Cheung, 2015a, 2015b). The iterations for the tested model and the parameters converged with no errors in the analysis as the OpenMx 
Status was 0 , which shows that the results are the best solution for the given data (Cheung 2015a, 2015b).

We summarize the results in Figure 6 and report the detailed analysis in Table S9 in the Supplementary Material. Consistent with our hypotheses, perceived risks negatively predicted political efficacy $(\mathrm{H} 3 \mathrm{a} ; \beta=-.08, S E=.03, p=.025,[-.147,-.010])$, and positively predicted fear $(\mathrm{H} 1 ; \beta=.48, S E=.03, p<.001,[.417, .537])$, outrage $(\mathrm{H} 2 ; \beta=.40, S E=.03, p$ $<.001,[.338, .467])$, identity consolidation efficacy $(\mathrm{H} 4 \mathrm{a} ; \beta=.16, S E=.04, p<.001$, $[.094, .233])$, participative efficacy $(\mathrm{H} 5 \mathrm{a} ; \beta=.11, S E=.03, p=.002,[.041, .177])$, politicized identification $(\mathrm{H} 6 ; \beta=.29, S E=.03, p<.001,[.229, .352])$, and moral obligation $(\mathrm{H} 7 ; \beta$ $=.11, S E=.03, p=.002,[.042, .179])$

Regarding the prediction of moral obligation, in line with our hypotheses, politicized identification $(\mathrm{H} 7 ; \beta=.35, S E=.03, p<.001,[.290, .409])$, participative efficacy (H8; $\beta$ $=.19, S E=.03, p<.001,[.134, .246])$, and outrage $(\mathrm{H} 11 ; \beta=.16, S E=.03, p<.001$, $[.106, .221])$ were positive predictors. Identity consolidation efficacy $(\mathrm{H} 7 ; \beta=.06, S E=.03$, $p=.052,[-.001, .118])$ and political efficacy $(\mathrm{H} 10 \mathrm{a} / \mathrm{b} ; \beta=-.04, S E=.03, p=.144$, $[-.096, .014])$ did not predict moral obligation. Finally, moral obligation $(H 13 ; \beta=.30, S E$ $=.04, p<.001,[.235, .369])$ positively predicted collective action intentions. Disconfirming H12, fear $(\beta=-.04, S E=.03, p=.233,[-.095, .023])$ did not predict action intentions (please refer to Table 9 for a summary of the tested hypotheses across the four contexts and the MetaSEM).

Perceived risks indirectly predicted collective action $(.16,[.104, .217])$ specifically through outrage $(.05,[.027, .080])$, identity consolidation efficacy $(.03,[.014, .044])$, politicized identification $(.06,[.040, .087])$, and moral obligation $(.03,[.012, .057])$. Furthermore, outrage $(.05,[.030, .072])$, participative efficacy $(.06,[.038, .081])$, and 
politicized identification $(.11,[.078, .137])$ indirectly predicted collective action intentions through moral obligation.

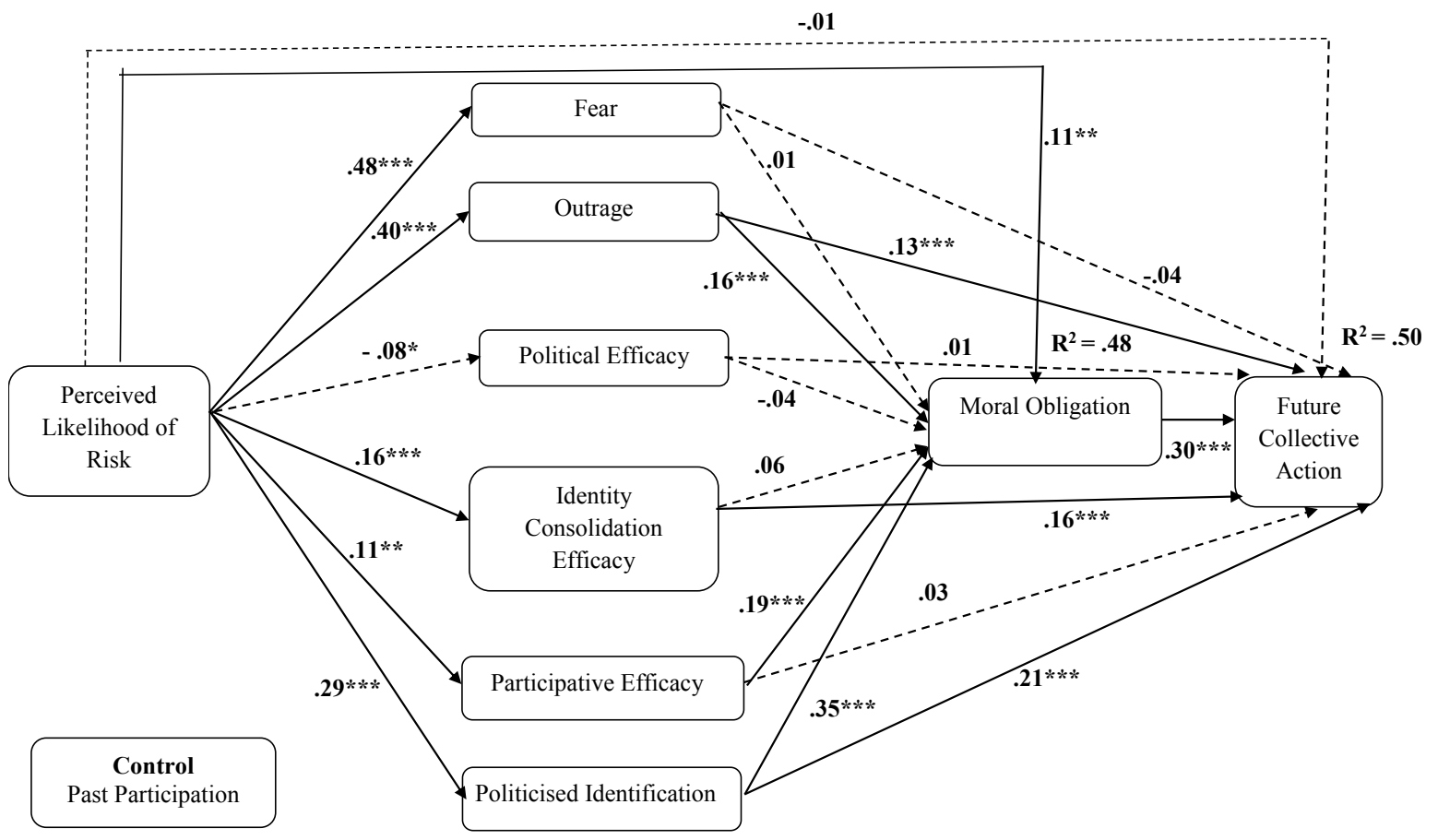

Figure 6: Results of Meta-SEM. The coefficients are the standardized regression estimates. $* \mathrm{p}<.05, * * \mathrm{p}<.01, * * * \mathrm{p}<.001$. Past involvement in protests was considered as covariate. Past involvement positively predicted outrage $(\beta=.27 * * *)$, political efficacy $(\beta=.27 * * *)$, identity consolidation efficacy $\left(\beta=.21^{* * *}\right)$, participative efficacy $\left(\beta=.15^{* * *}\right)$, politicized identification $\left(\beta=.35^{* * *}\right)$, moral obligation $(\beta=.18)$, and collective action $\left(\beta=.15^{* * *}\right)$. 


\begin{tabular}{cccccc}
\hline \hline & & & Studies & & \\
& 1:Russia & 2: Ukraine & 3: Hong Kong & 4: Turkey & MetaSEM \\
\hline Hypotheses & & & & & \\
H1 & $\checkmark$ & $\checkmark$ & $\checkmark$ & $\checkmark$ & $\checkmark$ \\
H2 & $\checkmark$ & X & $\checkmark$ & $\checkmark$ & $\checkmark$ \\
H3 a/b & $\checkmark($ a & X & $\checkmark(b)$ & X & X \\
H4 a/b & X & X & $\checkmark(b)$ & $\checkmark(b)$ & $\checkmark(b)$ \\
H5 a/b & $\checkmark(b)$ & X & $\checkmark(b)$ & X & $\checkmark(b)$ \\
H6 & $\checkmark$ & X & $\checkmark$ & $\checkmark$ & $\checkmark$ \\
H7 & $\checkmark$ & $\checkmark$ & $\checkmark$ & $\checkmark$ & $\checkmark$ \\
H8 & X & $\checkmark$ & $\checkmark$ & $\checkmark$ & $\checkmark$ \\
H9 & $\checkmark$ & X & $\checkmark$ & X & X \\
H10 a/b & $\checkmark(b)$ & X & X & X & X \\
H11 & $\checkmark$ & X & $\checkmark$ & X & $\checkmark$ \\
H12 & $\checkmark$ & X & X & $\checkmark$ & X \\
H13 & $\checkmark$ & $\checkmark$ & $\checkmark$ & $\checkmark$ & $\checkmark$ \\
\hline
\end{tabular}

\section{General Discussion}

Social psychological theorizing on collective action has progressed considerably over the past decade (see van Zomeren, 2016), yet empirical work on this topic has been limited to relatively low-risk actions in democratic and liberal Western countries. Consequently, the wider applicability of the emerging models is uncertain (see Opp, 2009), especially with respect to the motivators of collective action in repressive contexts. The present research aimed to address this limitation and pursued three main goals.

First, we specified a comprehensive predictive model of collective action intentions, which takes into account recent theoretical developments by distinguishing different emotions, dimensions of efficacy, and politicized identification as key antecedents, and examined its value in predicting collective action intentions in four different contexts marked by high levels of repression of activism. The model had high explanatory power, accounting for between $46 \%$ (Ukraine) and $72 \%$ (Russia) of the variability in collective action intentions. 
In line with much other work on collective action (Leach et al., 2006; Stürmer \& Simon, 2004; van Zomeren et al., 2008), our findings generally confirm the importance of politicized identification and outrage as motivating factors.

However, political efficacy, which is considered a key factor in motivating action across different literatures (Mummendey et al., 1999; Nepstad, 2011; van Zomeren et al., 2008), was found to be overall non-significant as a predictor in the present contexts, indicating that the belief that collective action will achieve its stated political goal might be less important in motivating participation in repressive contexts. Rather, action intentions were a function of the belief in the action's ability to build a broader movement (identity consolidation efficacy) as well as belief in the importance of one's personal contribution (participative efficacy). This suggests that, although political efficacy is not a predictor, collective action in repressive contexts is still strategic, as the factors that pave the way for future organization and resistance (see also Drury, Evripidou, \& van Zomeren, 2014; Hornsey et al., 2006; Klein et al., 2007) might be more relevant than the direct political impact of action under these circumstances.

In fact, the belief that forming such a movement is possible even though it might attract "targeted" repression, might result from the belief that mass protests would raise awareness about the pressing grievances and provide proof of the illegitimacy of the government, consequently would attract national, international and media attention as well as support for the protest movement and formation of new alliances (Araj, 2008; Chang, 2008; Sutton, Butcher, \& Svensson, 2014; Wisler \& Giugni, 1999). We acknowledge though, that such thinking might be contingent upon individuals highly valuing the social and economic demands as well as having an ideology aligned with the demands and/or the movement (see DeNardo, 1985). We also acknowledge that repression may increase political or identity consolidation efficacies up to a certain level, up until repression is so high that even virtual 
resistance is impossible, activism consumes all available resources, and individuals start feeling hopeless (DeNardo, 1985; Gurr, 1970; Muller \& Weede, 1990).

Thus, our findings further underline the importance of assessing a range of criteria for the efficacy of collective action and call for the necessity to explore the factors which render political efficacy non-significant as a motivator of collective action in such contexts.

Following Cichocka et al. (2018), including macro-level contextual factors (e.g., properties of the political regime) while exploring the role of external (i.e., political system being open to demands) and collective political efficacies in curvilinear relationships between system justification and collective action is one potential avenue for future research. It is further notable that the emotion of fear, which previous laboratory-based research has found to be a strong inhibitor of collective action (Miller et al., 2009), did not emerge as a significant predictor of action in the present research and in one study (Turkey) even positively predicted action intentions.

While this seems counter-intuitive and inconsistent with theory on the role of emotions in shaping behavior (Dumont, et al. 2003), a number of approaches can account for this finding. According to emotion theory and previous research, fear can sometimes lead to (defensive) aggressive or confrontational action, especially when the opponent is an outgroup threatening one's in-group (Simunovic, Mifune, \& Yamagishi, 2013; Spanovic, Lickel, Denson, \& Petrovic, 2010). Moreover, psychological reactance theory argues that infringements on one's freedom can lead to defensive reactions as well as backlash (Brehm \& Brehm, 1981), and Witte $(1992,1996)$ hypothesized that when the perceived threat and perceived efficacy to confront the threat is high, fear would predispose individuals to be more prone to cognitively and deliberately confront the danger. He further hypothesizes that fear can lead to a boomerang effect when the threat is excessive and the perceived efficacy is low. These effects might be particularly strong in repressive contexts, since the existence of the 
group is directly threatened and not acting might signal hesitation and encourage even harsher repression in the future. The overall null effect of fear as a predictor in the present research might result from different people reacting in different ways to the perceived repression.

The second goal of our research was to determine how the risks associated with activism feed into the psychological antecedents of collective action and thus impact on willingness to get engaged. Consistent with the idea of a backlash effect of repression (e.g., Hess \& Martin, 2006), we found that the perceived risks attached to activism positively predicted future action tendencies, over and above current involvement, and that this was explained through outrage, increased politicized identification, and increased identity consolidation and participative efficacies. These findings shed some light on the so-called “micro-mobilization" processes that are assumed to underlie this effect (Opp, 1990). Specifically, our findings suggest that state repression galvanizes protesters because it arouses feelings of outrage, strengthens commitment to the attacked social movement, heightens people's perception that their own contribution is valuable and strengthens the belief that broader support for the movement can be garnered through further action. Interestingly, we found little evidence overall and a consistent pattern only in Russia of a deterrent effect through the arousal of fear in our data. While perceived risk was a strong predictor of fear, as we had hypothesized, fear did not emerge as a predictor of action as discussed above.

The third goal of the current work was to further explore the importance of a sense of moral obligation in motivating engagement. Based on some initial work on this construct (Nepstad, 2004; Opp, 1994; Stürmer \& Simon, 2004; Vilas \& Sabucedo, 2012), we considered moral obligation to be the most proximal antecedent of collective action in our model. Consistent with this prior work, we found moral obligation to be a significant 
predictor of action intentions and to partially mediate the effects of identification, efficacy, and emotion. Thus, our work further highlights the importance of group processes in creating a sense of obligation to act (Atran, 2016; Atran \& Ginges, 2015; Stürmer \& Simon, 2004, Villas \& Sabucedo, 2012). Interestingly, the inclusion of this variable allowed us to further understand the relationship between political efficacy and action intentions, which varies widely in the literature (e.g., see Tausch et al., 2011; van Zomeren et al., 2008). In Study 1 we obtained a negative indirect relation between political efficacy and action intentions via moral obligation, which suggests the existence of a "free rider effect" (Olson, 1968) whereby the experienced obligation to act is reduced to the extent to which individuals feel that the protest movement will achieve its goals. Future research needs to further explore this link and its moderators to shed light on the conditions and individual factors that determine when and why a sense of duty to support a social movement is aroused or undermined.

\section{Limitations of the Present Research}

We acknowledge a number of limitations of this research. First, we relied on internetbased convenience samples rather than on random or nationally representative ones, which limits the generalizability of our findings. However, our purpose was primarily to understand how activists and individuals with a certain level of past participation in collective action respond to perceived risks, and why they engage in high-risk collective action. Furthermore, the practical constraints of conducting research in such risky and highly dynamic contexts made other forms of data collection difficult. Note however that research has underlined the validity and contribution of 'internet' samples (Gosling, Vazire, Srivastava, \& John, 2004).

Furthermore, although, the main aim of the current research was to assess the role of repression in shaping the willingness to get engaged for individuals who were already or likely to be involved in the protest movements under investigation, it is important to test the hypothesized predictions in the vast majority of the population who have no past experiences 
of collective action and who typically refrain from protesting. Future studies should examine whether repression spurs protests not only for a small percentage of devoted activists but also within the mainstream population, or whether repression has a deterring effect for those who have no past experiences of collective action. For instance, as politicized identification emerged as one of the most significant predictors of action intentions under risk, future research can examine whether in-group norms of resisting risks, helping fellow in-group members in times of need, and/or overcoming fear shape individuals' motivation to take action. In fact, previous research has highlighted how in-group norms shape the costs and benefits that are considered important (Hornsey, Blackwood, \& O’Brien, 2005; Livingstone \& Haslam, 2008; Louis, Taylor, \& Douglas, 2005), as well as emotions and beliefs (Thomas McGarty, \& Mavor, 2009).

Conversely, related to identity and norms, one can speculate that people who are already highly involved in the movement might have internalized the emotional, efficacy and identity norms of the movement (Thomas et al., 2009), making it less likely that these will be shifted as a function of perceived risks. Rather, it is people on the side lines of a movement who respond most strongly to the imposition of risk and are drawn further into activism. Hence, considering past participation as a moderator, extending the present work to nonactivist population, and systematically comparing non-activists and activists through experimental and longitudinal studies is important as the relations between variables might be different for a non-activist population. To explain how various populations respond to perceived risks and how this shapes willingness to challenge or promote the state, one can also consider the role of system-level emotions (Solak, Jost, Suemer, \& Clore, 2012). Positive system-level emotions such as pride, admiration, and gratitude regarding the system may alleviate the perception of the gravity of the use of repression against system-challengers and tamper the outrage towards this repression. 
Second, our reliance on cross-sectional data precludes inferences about the causal relations between these variables and does not allow us to rule out the influence of third variables that were not directly controlled for. This is a common problem in field research on collective action, which does not easily lend itself to experimentation. To address the issue of causality at least partly, we included a measure of current activism as a control variable in all models to ensure that the observed relationships represent shifts in action intentions over and above previous levels of involvement. Hence, the possibility that level of involvement can act as a third variable that can explain relations between the variables (e.g., perceived risks and emotions) is reduced, and the presented associations are all based on the residuals of regression between past participation and the various dependent variables.

Moreover, although our analyses were guided by established theory and prior research, we acknowledge that the causal relations between variables are also likely to be reciprocal and some variables are likely to arise more or less simultaneously. Alternative specifications therefore cannot be excluded, and further experimental and longitudinal studies are required. For example, while our focus on prediction led us to consider politicized identification at the same level as the other antecedents, two recent integrative models of collective action, the social identity model of collective action (SIMCA; van Zomeren et al., 2008) and the encapsulated model of social identity in collective action (EMSICA; Thomas et al., 2009, 2011) offer alternative specifications of the role of this variable. Specifically, while SIMCA considers identification to be an antecedent of injustice and efficacy perceptions, EMSICA suggests that identification is an outcome of these variables as outrage and efficacy perceptions may motivate individuals to identify with a movement. Consistent with Thomas et al., (2012), we suspect that different causal specifications might be valid in different contexts and/or relevant to people who are at different stages of involvement in collective action. One might argue that EMSICA is more relevant for individuals who are at the early 
stages of their involvement (Thomas et al., 2009, 2012), while SIMCA (van Zomeren et al., 2008) could be more pertinent for more 'seasoned' activists, since their identification with the protest movement can further feed into their outrage and efficacy beliefs. As we anticipated our samples to include activists at different stages of their involvement, we considered politicized identification to be at the same level as the remaining antecedents of collective action, and moral obligation as the most proximal predictor of collective action.

In the same line, the current model considers moral obligation as the most proximal predictor of collective action (Sabucedo et al., 2018; Sabucedo, Dono. Grigoryev, GómezRomán, \& Alzate, 2019), although we acknowledge that Milesi and Alberici (2016) have suggested and provided support for politicized identification being the most proximal predictor of collective action and moral obligation a predictor of politicized identification.

Although we suggest alternative models, our results across the four contexts and MetaSEM advocate a direct link between the antecedents of collective action and action intention that are not fully mediated by moral obligation. Hence, while we propose different models which are theoretically possible, there is clear evidence in our datasets that moral obligation is a proximal predictor of collective action and that moral obligation and politicized identification are distinct constructs with unique explanatory power.

Interactive relationships between the key variables are also plausible. While considering this question in detail is beyond the scope of the present paper, a number of supplementary analyses indicate that both perceived risk and politicized identification can moderate the impact of other variables on collective action tendencies ${ }^{10}$. For example, the

\footnotetext{
${ }^{10} \mathrm{We}$ conducted a series of analyses testing for the potential moderating role of likelihood of risk using PROCESS Model 59 for multiple moderated-mediation models. In Study 2, political efficacy significantly interacted with likelihood of risks in predicting moral
} 
obligation $(-15, S E=.07, p=.033,[-.289,-.012])$, such that political efficacy significantly predicted moral obligation only at low levels of perceived risks $(B=.26, S E=.10, p=.010$, $[.064, .465])$, and moral obligation was not a significant mediator in the relation between political efficacy and collective action at any level of perceived risks. Identity consolidation efficacy significantly interacted with likelihood of risks in predicting moral obligation (-18, $S E=.09, p=.037,[-.350,-.011])$. However, the simple slopes were not significant. When looking at the pattern, identity consolidation efficacy was positively associated with moral obligation at low and moderate levels of risks and negatively at high levels. Moral obligation was not a significant mediator in the relation between identity consolidation efficacy and collective action at any level of perceived risks. In Study 3, political efficacy interacted with perceived risks in predicting moral obligation $(-.13, S E=.05, p=.017,[-.243,-.025])$.

Political efficacy negatively predicted moral obligation only at high levels of perceived risks $(B=.17, S E=.07, p=.018,[-.301,-028])$. Moral obligation was not a significant mediator at any level of perceived risks. No other interactions were significant.

We conducted a simple moderation (model 1), where we examined the moderation effect of likelihood of risk in the relation between moral obligation and collective action. In Study 2, the interaction was significant $(.13, S E=.06, p=.028,[.014, .239])$. Moral obligation predicted collective action only at high levels of likelihood of risks $(B=.28, S E=.10, p$ $=.008,[.072, .482])$. In Study 3 , moral obligation significantly interacted with likelihood of risk $(-.17, S E=.05, p=.001,[-.265,-.069])$, and predicted collective action at low $(B=.38$, $S E=.11, p=.001,[.155, .608])$ and moderate $(B=.24, S E=.11, p=.038,[.013, .485])$ levels of perceived risks. 
results of the moderation analyses across the contexts showed very few significant interactions and an inconsistent pattern that varied across contexts. The significant interactions obtained suggest perceived risks to play a significant moderating role in the relation between political efficacy and moral obligation, but in different ways in different contexts. When risks are low, political efficacy positively predicts moral obligation in Study 2, however, at very high levels, it negatively predicts moral obligation in Study 3. Moreover, moral obligation was a significant positive predictor of collective action at high levels of risks in Study 2, and at low and moderate levels in Study 3. These results suggest that the impact of risk, particularly whether or not the free rider effect emerges and whether a sense of obligation leads to action, varies across contexts. Future research is needed to shed light on this and explore the potential factors leading to these differences. In line with the curvilinear effect, contextual factors such as the level and length of time of repression might be of relevance.

Moreover, politicized identification moderated some paths from perceived risks. Specifically, in Studies 3 and Study 4 perceived risk predicted some of the antecedents of collective action only at low and moderate levels of politicized identification (i.e., outrage and moral obligation in Hong Kong and identity consolidation efficacy in Turkey), suggesting that highly identified individuals, who are likely to have internalized the emotional and efficacy norms of the movement, might be less affected by repressive actions. Moreover, activists probably already hold specific (negative) views of the authorities, and the use of repression only confirms their views. However, in Study 4 (Russia), for participants who were highly identified, perceived risks actually negatively predicted their identity consolidation efficacy. Within the Russian context, repression has been present for years, hence, those who highly identify with the movement might also be very knowledgeable of the resources and possibilities to further consolidate their movement when repression is very 
high. Consequently, their efficacy beliefs decrease. The fact that we found only few significant interactions can be due to the cross-sectional nature of the data as well as power issues. Future research could examine these patterns further using longitudinal and experimental designs.

Finally, even though our model explained a substantial amount of variance in collective action intentions, we should emphasize that the current work does not represent a complete analysis of the factors underlying collective action in high-risk contexts. While we focused on the three main groups of explanatory variables (see van Zomeren et al., 2008), a range of other factors, such as existing social networks and levels of political knowledge (Louis, Amiot, Thomas, \& Blackwood, 2016), as well as experienced positive emotions such as pride (Tausch \& Becker, 2013) are likely to play a role and could be considered in followup studies. Reciprocal emotions and affective ties within a movement (e.g., love and loyalty, Jasper, 1997, 1998) may also be of relevance in initiating and sustaining action under high risk (DiGrazia, 2014; Jasper, 1998; Loveman, 1998; Nepstad, 2004; Nepstad \& Smith, 1999; Opp \& Roehl, 1990).

An important future step is to include ideological constructs in our model such as political ideology and system justification as these constructs shape how people perceive and respond in a particular context/conflict and the alignment of one's political ideologies and the ideology and values conveyed in a protest movement is an important factor in motivating one to get politically engaged and sustain one's engagement (Jost, Becker, Osborne, \& Badaan, 2017; Klandermans, Werner, \& van Doorn, 2008; Langer, Jost, Bonneau et al., 2019; Osborne, Jost, Becker, Badaan, \& Sibley, 2017; van Stekelenburg \& Klandermans, 2007, 2010). For instance, ideological beliefs, values, and norms can shape participants' perception of risks, political efficacy, moral obligation, and dynamics among protesters and between protesters and the authorities (e.g., choice of violent vs non-violent collective action) (see 
Langer, et al., 2019; Jost, Chaikalis-Petritsis, Abrams, Sidanius et al., 2012; Jost et al., 2017). For instance, in this project, the protest movements in Russia, Hong Kong and Turkey targeted political repression, however, the Ukrainian protest movement, during the period the survey took place, targeted specific governmental policy. Hence, these protests had different ideological goals. Such differences might explain some of the differences we found between the countries. Ayanian and Tausch (2016) found repression to have differential effects on protesters' efficacy and emotions depending on their political orientation (i.e., anti-Morsi or anti-Military). Moreover, individual differences in beliefs in the fairness of the system would address issues related to why political efficacy might increase but also indirectly decrease collective action (Osborne et al., 2015), as well as why some individuals feel outraged and morally obliged to protest against the repression and others do so to a lesser extent or even decide to engage in counter-protests to defend the system. The system-level emotions (i.e., hope, pride) mentioned above can also mediate the relation between perceived risks, politicized identification, ideological or system justifying beliefs, and engagement in collective action (Langer et al., 2019).

Furthermore, research has shown a link between moral reasoning, political affiliation, and activism (Gross, 1996; Moreira, Rique Neto, Sabucedo, \& Camino, 2018). Schwartz (1977) argued for the role of personal values and norms in shaping one's moral obligation to engage in any action. Social values have been linked to moral obligation and altruistic and environmental behavior (Kaiser \& Byrka, 2011; Lönnqvist, Walkowitz, Wichardt, Lindeman, \& Verkasalo, 2009; van Lange, de Bruin, Otten, \& Joireman, 1997). Recently, Sabucedo et al. (2019) tested the role of left vs right ideologies and politicized identification in shaping participants' efficacy, affective injustice, and moral obligation, and considered actual participation in conventional action (i.e., voting; Study 1), and willingness to engage in nonconventional action (i.e., cutting off traffics; Study 2) as dependent variables. Their results 
confirmed ideology to negatively predict moral obligation (Study 2) and collective action (Study 1, 2). Moreover, moral obligation was a positive predictor of action in both studies. Hence, the inclusion of such ideological and individual-level constructs would ensure a more comprehensive and integrative model of collective action in repressive contexts and would be highly relevant when extending the model to non-activist samples.

\section{Contributions and Directions for Future Research}

Notwithstanding these limitations, we believe that the present research makes a number of valuable contributions to the literature on collective action. To our knowledge, the current research is one of the few comprehensive empirical investigations of the predictors of collective action tendencies in contexts where protesters face substantial risks due to state repression. Unlike past research, which was predominantly conducted in WEIRD (western, educated, industrialized, rich, and democratic; Henrich, Heine, \& Norenzayan, 2010; Rad, Martingano, \& Ginges, 2018) contexts, this paper presents some of only a handful of studies on the social-psychological predictors of collective action in high-risk contexts (for exceptions see Ayanian \& Tausch, 2016; Baysu \& Phalet, 2017; Gulevich, Sarieva, Nevruev, \& Yagiyayev, 2017; Chayinska, Minescu, \& McGarty, 2017). These data are unique given the practical difficulty of gathering data from activists in such contexts. Our findings suggest that the predictive variables identified in prior research overall explain a substantial amount of variance in collective action tendencies, but also point to the relatively low importance of political efficacy and fear as psychological motivators. These results highlight the importance of testing the generalizability of our models in a variety of contexts and call for the development of more contextualized theories (see also van Zomeren \& Louis, 2017). Our research also contributes to our understanding of what is considered one of the main unsolved puzzles in the wider collective action literature, namely the question of why people take to the streets in the face of severe repression (Opp, 2009). Although the role of repression has 
been extensively examined at the macro- and meso-level, one cannot fully understand how repression shapes resistance without examining the underlying social psychological processes set in motion (Opp, 2009). Through considering perceived risks a self-relevant micro-level manifestation of repression, we were able to demonstrate how repression can galvanize resistance, and point to processes that may determine why repression sometimes works and sometimes does not (see also Honari, 2017).

These initial findings open up potentially fruitful avenues for future research in social psychology. Scholars in political science and sociology argue, for example, that different types of authority sanctions (institutional/long vs situational/short term) can have differential effects on social movements and dissent (Wiltfang \& McAdam, 1991). For instance, longitudinal and subtle forms of sanctions (e.g., surveillance) are very effective in confining collective action, since these measures restrain an opposition movement to develop, without endangering the authorities' legitimacy (Barkan, 2006; Boykoff, 2007). On the other hand, situational or short term repression (e.g., violent police intervention during protests) can be perceived as illegitimate and indiscriminate, consequently spurring further resistance (see also Moore, 1998; Rasler, 1996). By specifically measuring the micro-mobilization processes involved in resistance, social-psychological research can provide important new insights into the effectiveness of different forms of repression and how to best mobilize resistance against them.

For instance, reactance (Brehm \& Brehm, 1981) might be part of the backlash effect demonstrated in the present work. Following Laurin, Kay, and Fitzsimons (2012) work on rationalization (Aronson, 1973) and reactance (Brehm \& Brehm, 1981), certainty of implementation of repression might moderate the relation between perceived risks and willingness to engage in collective action. Specifically, when repression is perceived as absolute hindering of freedoms with certainty of implementation, individuals would tend to 
rationalize the use of force and refrain from engagement in collective action. However, when the measures are not absolute and are uncertain, they might react to the use of repression or restrictions of freedom with valuing highly the freedom of expressing oneself and engaging in collective action, and consequently be willing to engage in action.

Moreover, the inverted-U curve (DeNardo, 1985; Gurr, 1970; Muller \& Weede, 1990), a theoretical model that aims to explain the link between repression and dissent, suggests that mobilization initially increases as a response to modest levels of repression and decrease once repression reaches a certain level. An important future direction is to examine whether such curvilinear relationship also exists at a micro-level. Specifically, it would be interesting to explore what level of repression leads to further collective action through which micro-mobilization processes, and at which level of repression action decreases and through which processes this occurs. Considering activists' adaptation strategies to repression, and government's past accommodation and repression strategies (Davenport, 2007; Moore, 2000; Moss, 2014) might contribute to an understanding of the differential effects of repression. Furthermore, research showed that the form of government might affect the relationship between repression and dissent (Abadie, 2004; Davenport, 2007). Specifically, in both highly autocratic regimes, typically characterized with very high levels of repression, and democratic governments, typically characterized with low levels of repression, resistance is the least likely. Furthermore, scholars have also emphasized the bidirectional relationship between dissent and repression, whereby resistance leads to repression, and repression in its turn leads to more resistance (Carey, 2006). Future studies should examine how such macrolevel factors affect the micro-level individual motivations of protesters in engaging in further action. 


\section{Conclusion}

The present research fills an important gap in the literature by testing a comprehensive predictive model of collective action tendencies across a range of high-risk contexts. It provides evidence consistent with a galvanizing effect of state repression on individuals' willingness to engage in high-risk collective action and delineates some of the "micro-mobilization" processes underlying this effect. Our results have implications that help shape the collective action frames that are likely to incite willingness to engage in collective action under risk (Reicher et al., 2006) and should therefore be of interest to protest movement organizers and activists in general who wish to mobilize resistance in contexts where authority repression is prevalent. 


\section{References}

Abadie, A. (2004). Poverty, political freedom, and the roots of terrorism. NBER Working Paper no. 10859. National Bureau of Economic Research. Downloaded from: http://www.nber.org/papers/w10859

Acar, Y. G. \& Coşkan, C. (2020). Academic activism and its impact on individual-level mobilization, sources of learning, and the future of academia in Turkey. Journal of Community and Applied Social Psychology. Accepted for publication.

Acock, A. C. (2005). Working with missing values. Journal of Marriage and family, 67(4), $1012-1028$.

Alberici, A. I., \& Milesi, P. (2018). Online Discussion and the Moral Pathway to Identity Politicization and Collective Action. Europe's Journal of Psychology, 14(1), 143. doi: $10.1177 / 1368430215581430$

Alexander, H. (2013, October 2). Turkish police in Taksim protests accused of brutality. The Telegraph. Retrieved from:

http://www.telegraph.co.uk/news/worldnews/europe/turkey/10347991/Turkish-policein-Taksim-protests-accused-of-brutality.html

Amnesty International (2014, October, 20). Eastern Ukraine conflict: Summary killings, misrecorded and misreported. Retrieved from:

https://www.amnesty.org/en/latest/news/2014/10/eastern-ukraine-conflict-summarykillings-misrecorded-and-misreported/

Amnesty International (2015, March 27). Turkey: Draconian reforms give police wideranging powers to repress dissent. Retrieved from: https://www.amnesty.org/en/latest/news/2015/03/turkey-gives-police-broad-powers-torepress-dissent/

Araj, B. (2008) Harsh state repression as a cause of suicide bombing: The case of the 
Palestinian-Israeli conflict. Studies in Conflict \& Terrorism, 31(4), 284-303, doi: $10.1080 / 10576100801925273$

Aronson, E. (1973). The rationalizing animal. In H. J. Leavitt, L. R. Pondy, \& D. M. Boje (Eds.), Readings in managerial Psychology (4th ed, pp. 134-144). Chicago: University of Chicago Press

Atran (2016). The devoted actor: Unconditional commitment and intractable conflict across cultures. Current Anthropology, 57(13), 192- 203. doi:10.1086/685495

Atran, S. \& Ginges, J. (2015). Devoted actors and the moral foundations of intractable intergroup conflict. In Decety, J., \& Wheatley, T. (Eds), The moral brain: A multidisciplinary perspective, pp. 69-86. The MIT Press.

Ayanian, A.H., \& Tausch, N. (2016). How risk perception shapes collective action intentions in repressive contexts: A study of Egyptian activists during the 2013 post-coup uprising. British Journal of Social Psychology, 55(4), p. 700-721. doi:10.1111/bjso. 12164

Ayanian, A.H., \& Tausch, N. (2013). Egyptian activists ' accounts on discounting risks imposed by state repression of collective action. Unpublished dataset.

Bandura, A. (1991). Social cognitive theory of moral thought and action. In W. Kurtines, \& J. Gewirtz (Eds.), Handbook of moral behavior and development (Vol 1, pp. 45-103). Hillsdale, NJ: Lawrence Erlbaum.

Balmforth, R. (2014). Ukraine to bring back compulsory military service: Ukraine defense council. Reuters. Retrieved from https://www.reuters.com/article/us-ukraine-crisismilitary/ukraine-to-bring-back-compulsory-military-service-ukraine-defense-councilidUSKBN0GS26320140828 
Barber, E. (December, 2014). Hong Kong protests reach violent high as students clash with police overnight. Time. Retrieved from: http://time.com/3611250/hong-kong-occupycentral-umbrella-revolution-lung-wo/

Barkan, S. (2006). Criminal prosecution and the legal control of protest. Mobilization: An International Quarterly, 11(2), 181-194. doi: 10.17813/maiq.11.2.a8671t532kww2722

Barry, E., \& Schwirtz, M. (2012). Arrests and violence at overflowing rally in Moscow. The New York Times. Retrieved from:

http://www.nytimes.com/2012/05/07/world/europe/at-moscow-rally-arrests-andviolence.html

Başer, B., Akgönül, S., \& Öztürk, A. E. (2017). “Academics for Peace” in Turkey: A case of criminalizing dissent and critical thought via counter-terrorism policy. Critical Studies on Terrorism, 10, 274-296.

Baysu, G., \& Phalet, K. (2017). Beyond Muslim identity: Opinion-based groups in the Gezi Park protest. Group Processes \& Intergroup Relations, 20(3), 350-366. https://doi.org/10.1177/1368430216682353

BBC news (2015, June 18). Hong Kong's democracy debate. Retrieved from: http://www.bbc.com/news/world-asia-china-27921954

Bebler (2015). The Russian-Ukrainian conflict over Crimea. Ifimes: International Institute for Middle East and Balkan Studies. Retrieved from: http:/www.ifimes.org/en/9035

Berman, S. L., \& Wittig, M. A. (2004). An intergroup theories approach to direct political action among African Americans. Group Processes and Intergroup Relations, 7, 1934. doi: $10.1177 / 1368430204039971$

Bilgin, F. (2013). Turkey: politics of the Gezi protests, Rethink Brief. Rethink Institute, Washington DC. Retrieved from: http://www.rethinkinstitute.org/files/Bilgin\%20-\%20Gezi\%20Protests.pdf 
Bischof, D., \& Fink, S. (2015). Repression as a double-edged sword: Resilient monarchs, repression and revolution in the Arab World. Swiss Political Science Review, 21(3), 377-395. doi: 10.1111/spsr.12169

Böcü, G. (2015). The Gezi generation: Youth, polarization and the new Turkey. In Schafer, I. (Ed). Youth, Revolt, Recognition: The Young Generation during and after the "Arab Spring”. Mediterranean Institute of Berlin. Retrieved from: http://edoc.huberlin.de/miscellanies/arabspring-41600/49/PDF/49.pdf

Boykoff, J. (2007). Limiting dissent: The mechanisms of state repression in the USA. Social Movement Studies: Journal of social, cultural and political protest, 6(3), 281-310. doi: $10.1080 / 14742830701666988$

Branigan, T. (2014, November). Hong Kong police clash with protesters targeting governments' buildings. The Guardian. Retrieved from: http://www.theguardian.com/world/2014/nov/19/hong-kong-police-protestersgovernment-buildings

Brehm, S. S. and Brehm, J. W. (1981) Psychological Reactance: A Theory of Freedom and Control. Academic Press, New York.

Brunsting, S., \& Postmes, T. (2002). Social movement participation in the digital age: Predicting offline and online collective action. Small Group Research, 33, 525-554. doi: $10.1177 / 104649602237169$

Buhi, E. R., Goodson, P., \& Neilands, T. B. (2008). Out of sight, not out of mind: strategies for handling missing data. American Journal of Health Behavior, 32(1), 83-92.

Cameron, J.E. (2004). A three factor model of social identity. Self and Identity, 3(3). 239262. doi: 10.1080/13576500444000047Cannon, W. B. (1932). The Wisdom of the Body. New York, NY: Norton 
Carey, S. C. (2006). The dynamic relationship between protest and repression. Political Research Quarterly, 59(1), 1-11. doi: 10.1177/106591290605900101

Chan, J. (2014). Hong Kong's Umbrella movement, The Round Table, 103(6), 571-580. doi: $10.1080 / 00358533.2014 .985465$

Chang, P.Y. (2008). Unintended consequences of repression: Alliance formation in South Korea’s Democracy Movement. Social Forces, 87(2), 651-677. doi: 10.1353/sof.0.0153

Chang, P. Y., \& Kim, B.S. (2007). Differential Impact of Repression on Social Movements: Christian Organizations and Liberation Theology in South Korea (1972- 1979). Sociological Inquiry. 77(3), 326-355. doi:10.1111/j.1475-682X.2007.00196.x

Chayinska, M., Minescu, A., \& McGarty, C. (2017). 'The more we stand for-the more we fight for': compatibility and legitimacy in the effects of multiple social identities. Frontiers in Psychology, 8, 642. doi: 10.3389/fpsyg.2017.00642

Chenoweth, E. (2015, June 10). Repression and backfire. Talk given at Fletcher Summer Institute for the Advanced Study of Nonviolent conflict [Youtube video]. Retrieved from: https://www.youtube.com/watch?v=j9MUxBLK1SI

Cheung, M. W-L. (2015a). Meta-Analysis: A Structural Equation Modeling Approach.

Chichester, West Sussex: John Wiley \& Sons, Inc.

Cheung, M. W-L. (2015b). MetaSEM: An R package for Meta-Analysis using structural equation modeling. Frontiers in Psychology, 5, 1-8. doi: 10.3389/fpsyg.2014.01521

Cheung, M. W-L, \& Cheung, S.F. (2014). Random effects models for meta-analytic structural equation modeling review: issues, and illustrations. Research Synthesis Methods, 7, 140- 155. doi: 10.1002/jrsm.1166 
Cheung, M. W-L. \& Hafdahl, A.R. (2016). Special issue on meta-analytic structural equation modeling: Introduction from the Guest Editors. Research Synthesis Methods, 7, 112120. https://doi.org/10.1002/jrsm.1212

Cichocka, A., Górska, P., Jost, J. T., Sutton, R. M., \& Bilewicz, M. (2018). What inverted U can do for your country: A curvilinear relationship between confidence in the social system and political engagement. Journal of personality and social psychology, 11(5), 883-902. doi: 10.1037/pspp0000168

Davenport, C. (2007). State repression and political order. Annual Review of Political Science, 10, 1-23. doi: 10.1146/annurev.polisci.10.101405.14321

Dearden, L. (2014). Ukraine crisis: A timeline of the conflict from the Euromaidan protests to MH17 and civil war in the east. The Independent. Retrieved from: http://www. independent.co.uk/news/world/europe/ukraine-crisis-a-timeline-ofthe-conflict-fromthe-euromaidan-protests-to-mh17-and-civil-war-in-the-east-9706999

Della Porta, D. (1992). Political socialization in left-wing underground organizations: Biographies of Italian and German militants. International Social Movement Research, 4(1), 259-290.

Demirjian, K. (2014, July). Meanwhile in Russia, Putin passes law against protests. The Washington Post. Retrieved from:

https://www.washingtonpost.com/news/worldviews/wp/2014/07/22/meanwhile-inrussia-putin-passes-law-against-protests/

Demirjian, K., \& Birnbaum, M. (2014). Russia escalates tensions with aid convoy, reported firing of artillery inside Ukraine. The Washington Post. Retrieved from https://www.washingtonpost.com/world/russian-humanitarian-convoy-enters-ukrainedespite-warnings/2014/08/22/7b14fa8e-29e1-11e4-8593da634b334390_story.html?utm_term=.bf09b253e654 
DeNardo, J. (1985). Power in numbers: The political strategy of protest and rebellion. Princeton: Princeton University Press.

Devos, T., Silver, L.A., \& Mackie, D.M. (2002). Experiencing intergroup emotions. In D.M., Mackie D.M. and E.R. Smith (Eds), From Prejudice to Intergroup Emotions: Differentiated Reactions to Social Groups. Philadelphia, PA: Psychology Press, 111134.

De Weerd, M., \& Klandermans, B. (1999). Group identification and political protest: Farmers` protests in the Netherlands. European Journal of Social Psychology, 29(8), 1073-1095.

DiGrazia, J. (2014). Individual protest participation in the United States: Conventional and unconventional activism. Social Science Quarterly, 95(1), 111-132. doi: $10.1111 /$ ssqu. 12048

Drury, J., Evripidou, A., \& van Zomeren, M. (2014). Empowerment: The intersection of identity and power in collective action. In D. Sindic, M. da Costa Barreto, \& R. Costa- Lopes (Eds.), Power and identity (pp. 94-116). (Current issues in social psychology). London; New York, NY: Psychology Press.

Drury, J., \& Reicher, S. D. (2000). Collective action and psychological change: The emergence of new social identities. British Journal of Social Psychology, 39(4), 579 604. doi: $10.1348 / 014466600164642$

Dudouet, V. (2015). Sources, functions and dilemmas of external assistance to civil resistance movements. In Kurt Schock (Ed), Civil Resistance: Comparative Perspectives on Nonviolent Struggle. Minneapolis, MN: University of Minnesota Press, ch.6, pp. 168203. 
Dumont, M., Yzerbyt, V., Wigboldus, D., \& Gordijn, E. (2003). Social categorization and fear reactions to the September $11^{\text {th }}$ terrorist attacks. Personality and Social Psychology Bulletin, 29(12), 1509-1520. doi:10.1177/0146167203256923

Earl, J. (2011). Political repression: Iron fists, velvet gloves, and diffuse control. The Annual Review of Sociology, 37, 261-284. doi:10.1146/annurev.soc.012809.102609

Earl, J., \& Soule, S.A. (2010). The impacts of repression: the effect of police presence and action on subsequent protest rates. Research in Social Movements, Conflicts and Change, 30, 75-113.

Enders, C. K. (2001). The performance of the full information maximum likelihood estimator in multiple regression models with missing data. Educational and Psychological Measurement, 61(5), 713-740.

Fischhoff, B., Watson, S.R., \& Hope, C. (1984). Defining risk. Policy Sciences, 17, 123-139. Retrieved from: http://sds.hss.cmu.edu/risk/articles/definingrisk.pdf

Fischhoff, B., Watson, S.R., \& Hope, C. (1984). Defining risk. Policy Sciences, 17, 123-139. Retrieved from: http://sds.hss.cmu.edu/risk/articles/definingrisk.pdf

Francisco, R. (1995). The relationship between coercion and protest: an empirical evaluation in three coercive states. Journal of Conflict Resolution, 39, 263-82. doi:10.1177/0022002795039002003

Francisco, R. (2004). After the massacre: Mobilization in the wake of harsh repression. Mobilization: An International Journal, 9(2), 107-26.

Fridja, N.H. (1986). The Emotions. Cambridge, England: Cambridge University Press.

Frijda, N. H., Kuipers, P., \& ter Schure, L. (1989). Relations among emotion, appraisal, and action tendency. Journal of Personality and Social Psychology, 57, 212-228. 
Folger, R. (1986). Rethinking equity theory: A referent cognitions model. In H.W. Bierhoff, R.L. Cohen and J. Greenberg J. (Eds). Justice in Social Relations. New York: Plenum, $145-162$.

Gel'man, V. (2015). Political opposition in Russia: A troubled transformation. Europe-Asia Studies, 67(2), 177-191. doi:10.1080/09668136.2014.1001577

Giugni, M. (1999). How social movements matter: past research, present problems, future developments. In: Marco Giugni, Doug McAdam, and Charles Tilly. How social movement matter. Minneapolis: University of Minnesota Press, xiii-xxxiii.

Downloaded from: https://archiveouverte.unige.ch/unige:92387/ATTACHMENT01f

Gross, M.L. (1996). Moral reasoning and ideological affiliation: a cross-national study. Political Psychology, 17, 317-338. doi: 10..2307/3791813

Goh, J., Hall, J., \& Rosenthal, R. (2016). Mini meta-analysis of your own studies: Some arguments on why and a prime on how. Social and Personality Psychology Compass, 10(10), 535-549. doi: 10.1111/spc3.12267

Gokay, B., \& Shain, F. (2013, August 26). The protests in Turkey: Urban warfare in 'rebel cities'. Open Democracy: Free Thinking for the World. Retrieved from: https://www.opendemocracy.net/bulent-gokay-farzana-shain/protests-in-turkey-urbanwarfare-in-rebel-cities

Gordijn, E.H., Wigboldus, D., \& Yzerbeyt, V. (2001). Emotional consequences of categorizing victims of negative outgroup behavior as ingroup or outgroup. Group Processes and Intergroup Relations, 4(4), 317-326.

Gordon, M. R. (2014). Russia Moves Artillery Units into Ukraine, NATO Says. The New York Times. Retrieved from 
https://www.nytimes.com/2014/08/23/world/europe/russia-moves-artillery-units-intoukraine-nato-says.html

Gosling, S. D., Vazire, S., Srivastava, S., \& John, O. P. (2004). Should we trust web-based studies? A comparative analysis of six preconceptions about internet questionnaires. American psychologist, 59(2), 93. doi: 10.1037/0003-066X.59.2.93

Greene, S. A. (2014). Moscow in movement: power and opposition in Putin's Russia. California: Stanford University Press.

Gross, M.L. (1996). Moral reasoning and ideological affiliation: a cross-national study. Political Psychology, 17, 317-338. doi: 10..2307/3791813

Gulevich, O., Sarieva, I., Nevruev, A., \& Yagiyayev, I. (2017). How do social beliefs affect political action motivation? The case of Russia and Ukraine. Group Processes and Intergroup Relations, 20(3), 382 - 395. doi: org/10.1177/1368430216683531

Gurr, T.R. (1970). Why men rebel. Centre of International Studies, Princeton University. Princeton University Press.

Hardin, R. (1982). Exchange theory on strategic bases. Social Science Information, 21(2), 251-272. doi:10.1177/053901882021002004

Harrington, J.C. (2015). Turkey: Democracy in peril. A human right report. Retrieved from: https:/hizmetnews.com/sds/wp-content/uploads/2017/10/Turkey-Democracy-in-PerilJC-Harrington.pdf

Hart, M. (2007). Humour and social protest: An introduction. International Review of Social History, 52(15), 1-20. doi:10.1017/S0020859007003094

Hedges, L.V., \& Vevea, J.L. (1998). Fixed and random effects models in meta-analysis. Psychological Methods, 3(4), 486-504. doi: http://dx.doi.org/10.1037/1082989X.3.4.486 
Henley, J. (2014, September 29). How the umbrella became a symbol of the Hong Kong democracy protests. The Guardian. Retrieved from https://www.theguardian.com/world/2014/sep/29/umbrella-symbol-hong-kongdemocracy-protests

Henrich, J., Heine, S. J., \& Norenzayan, A. (2010). Most people are not WEIRD. Nature, 466(7302), 29.

Hess, D., \& Martin, B. (2006). Repression, backfire, and the theory of transformative events. Mobilization: An International Journal, 11(2), 249-267.

Hirsch, (1990). Sacrifice for the cause: Group processes, recruitment, and commitment in a student social movement. American Sociological Review, 55(2), 243-254. Retrieved from www.jstor.org/stable/2095630

Hornsey, M., Blackwood, L., Louis, W., Fielding, K., Mavor, K., Morton, T., ... \& White, K.M. (2006). Why do people engage in collective action? Revisiting the role of perceived effectiveness. Journal of Applied Social Psychology, 36, 1701-1722. doi:10.1111/j.0021-9029.2006.00077.x

Hornsey, M. J., Blackwood, L., \& O’Brien, A. (2005). Speaking for Others: The Pros and Cons of Group Advocates using Collective Language. Group Processes \& Intergroup Relations, 8(3), 245-257. doi: 10.1177/1368430205053941

Honari (2017). Responses to repression. Sociopedia.isa (e-journal), doi:

\section{$0.1177 / 205684601751$}

Inglehart, R., Haerpfer, C., Moreno, A., Welzel, C., Kizilova, K., Diez-Medrano, J., Lagos, M., Norris, P., et al. (2014). World Values Survey: Round Six-Country-Pooled Datafile 2010-2014. JD Systems Institute, Madrid. 
International Federation for Human Rights and Anti-Discrimination Centre (2014). Russia 2012-2014: Attack on Freedom. Retrieved from:

https://www.fidh.org/IMG/pdf/rapport_russie_2012-2013_uk-ld_1_.pdf

Jasper, J.M. (1997). The art of moral protest: Culture, biography, and creativity in social movements. Chicago: University of Chicago Press.

Jasper, J.M. (1998). The emotions of protest: Affective and reactive emotions in and around social movements. Sociological Forum, 13: 397-424.

Jeffries, J. L. (Ed.). (2010). On the Ground: The Black Panther Party in Communities across America. Univ. Press of Mississippi.

Jenkins, C.J., \& Schock, K. (2004). Political process, international dependence, and mass political conflict. International Journal of Sociology, 33(4), 41-63. Retrieved from: http://www.jstor.org/stable/20628694

Jost, J. T., Becker, J., Osborne, D., \& Badaan, V. (2017). Missing in (collective) action: Ideology, system justification, and the motivational antecedents of two types of protest behavior. Current Directions in Psychological Science, 26(2), 99-108. doi: $10.1177 / 0963721417690633$

Jost, J. T., Chaikalis-Petritsis, V., Abrams, D., Sidanius, J., van der Toorn, J., \& Bratt, C. (2012). Why men (and women) do and don't rebel: effects of system justification on willingness to protest. Personality and Social Psychology Bulletin, 38(2), 197-208. doi: $10.1177 / 0146167211422544$

Kaiser, F. G. \& Byrka, K. (2011). Environmentalism as a trait: Gauging people's prosocial personality in terms of environmental engagement. International Journal of Psychology, 46, 71-79. doi: 10.1080/00207594.2010.516830 
Klandermans, B. (1984). Mobilization and participation: Social-psychological expansions of resource mobilization theory. American Sociological Review, 49, 583-600. Retrieved from: http://www.jstor.org/stable/2095417

Klandermans, B. (1997). The social psychology of protest. Oxford, England: Basil Blackwell.

Klandermans, B., \& van Stekelenburg, J. (2013). Social psychology and the dynamics of collective action. In L. Huddy, D.O. Sears, \& J.S. Levy (Eds.), The Oxford Handbook of the Political Psychology (2 ed.). Oxford University Press

Klandermans, P. G., Werner, M., \& van Doorn, M. (2008). Redeeming apartheid's legacy: Collective guilt, political ideology, and compensation. Political Psychology, 29(3), 331-349. doi: 10.1111/j.1467-9221.2008.00633.x

Klein, O., Spears, R., \& Reicher, S. (2007). Social identity performance: Extending the strategic side of the SIDE model. Personality and Social Psychology Review, 11(1), 28-45. doi:10.1177/1088868306294588

Koopmans, R. (1997). Dynamics of repression and mobilization: The German extreme right in the 1990s. Mobilization: An International Journal, 2(2), 149-164.

Krasavina, K. (2017, July 7). Russia tried to stop us from protesting. Human Rights Foundation. Downloaded from:

https://www.themaven.net/humanrightsfoundation/europe-russia/russia-tried-to-stopus-from-protesting-k10p2q-140m_xdAVH7HVVA

Kydd, A.H., \& Walter B.F. (2006). The strategies of terrorism. International security, 31(1), 49-80.

Lague, D., Torode, G., \& Pomfret, J. (2014, December 14). Special report: How China spies on Hong Kong's democrats. Reuters. Retrieved from http://www.reuters.com/article/2014/12/15/us-hong-kong-surveillance-special-reportidUSKBN0JT00120141215 
Langer, M., Jost, J. T., Bonneau, R., Metzger, M. M., Noorbaloochi, S., \& Penfold-Brown, D. (2019). Digital dissent: An analysis of the motivational contents of tweets from an Occupy Wall Street demonstration. Motivation Science, 5(1), 14-34. doi: $10.1037 / \operatorname{mot} 0000084$

Laurin, K., Kay, A. C., \& Fitzsimons, G. J. (2012). Reactance versus rationalization: Divergent responses to policies that constrain freedom. Psychological Science, 23(2), 205-209. doi: 10.1177/0956797611429468

Lazarus, R. S. (1991). Emotion and adaptation. New York: Oxford University Press.

Leach, W.C., Iyer, A., \& Pedersen, A. (2006). Anger and guilt about ingroup advantage explain the willingness for political action. Personality and Social Psychology Bulletin, 32(9), 1232-1245. doi:10.1177/0146167206289729

Lerner, J. S., \& Keltner, D. (2001). Fear, anger, and risk. Journal of Personality and Social Psychology, 81(1), 146-159. doi:10.1037/0022-3514.81.1.146

Lerner, J. S., \& Keltner, D. (2000). Beyond valence: Toward a model of emotion-specific influences on judgment and choice. Cognition and Emotion, 14, 473-493. doi: http://dx.doi.org/10.1080/026999300402763

Letsch, C. (2014, May 29). A year after the protests, Gezzi Park nurtures the seeds of a new Turkey. The Guardian. Retrieved from: https://www.theguardian.com/world/2014/may/29/gezi-park-year-after-protests-seedsnew-turkey

Linden, A., \& Klandermans, B. (2007). Revolutionaries, wanderers, converts, and compliants: Life histories of extreme right activists. Journal of Contemporary Ethnography, 36(2), 184-201. doi: 10.1177/0891241606298824

Little, R. J. (1988). A test of missing completely at random for multivariate data with missing values. Journal of the American statistical Association, 83(404), 1198-1202. 
Little, R. J. A., and Rubin, D.B. (2002). Statistical Analysis with Missing Data. 2nd ed. New York: Wiley

Livingstone, A. \& Haslam, S.A. (2008) The Importance of Social Identity Content in a Setting of Chronic Social Conflict: Understanding Intergroup Relations in Northern Ireland. British Journal of Social Psychology, 47, 1-21. doi:

\section{$10.1348 / 014466607 X 200419$}

Louis, W. R. (2009). Collective action and then what? Journal of Social Issues, 65(4), $727-$ 748. doi: 10.1111/j.1540-4560.2009.01623.x

Louis, W.R., Amiot, C.E., Thomas, E.F., \& Blackwood, L. (2016). The "activist identity" and activism across domains: A multiple identities analysis. Journal of Social Issues, 72(2), 242-263. doi:10.1111/josi.12165

Louis, W. R., Taylor, D. M. \& Douglas, R. L. (2005). Normative influence and rational conflict decisions: Group norms and cost-benefit analyses for intergroup behavior. Group Processes \& Intergroup Relations, 8(4), 355-374. doi:

\section{$10.1177 / 1368430205056465$}

Lönnqvist, J. E., Walkowitz, G., Wichardt, P., Lindeman, M., \& Verkasalo, M. (2009). The moderating effect of conformism values on the relations between other personal values, social norms, moral obligation, and single altruistic behaviors. British Journal of Social Psychology, 48(3), 525-546.

Loveman, M. (1998). High risk collective action: Defending human rights in Chile, Uruguay, and Argentina. American Journal of Sociology, 104(2), 477-525. doi:10.1086/210045

Luhmann, N. (1991). Technology, environment and social risk: A systems perspective. Industrial Crisis Quarterly, 4, 223-231. 
Lukyanova, Y. (2016). Manufacturing dissent in Russia: A discursive psychological analysis of protesters' talk (Unpublished doctoral thesis). University of Edinburgh, Edinburgh, UK.

Lyytikainen, L. (2013). Performing political opposition in Russia. Unpublished dissertation manuscript, University of Helsinki.

Mackie, D., Devos, T., \& Smith, E. (2000). Intergroup emotions: Explaining offensive action tendencies in an intergroup context. Journal of Personality and Social Psychology, 79(4), 602-616. doi:10.1037//0022-3514.79.4.602

Mackie, D. M., \& Smith, E. R. (2018). Intergroup emotions theory: Production, regulation, and modification of group-based emotions. In Advances in Experimental Social Psychology (Vol. 58, pp. 1-69). Academic Press.

Martin, B. (2007). Justice ignited: The dynamics of backfire. Lanham, MD: Rowman \& Littlefield.

Martin, B. (2015). From political Jiu-jitsu to the backfire dynamic: How repression can promote mobilisation. In K. Schock (Ed.), Civil resistance: Comparative perspectives on nonviolent struggle. Minneapolis, MN: University of Minnesota Press, Chapter 5, pp. $145-168$.

McAdam, D. (1986). Recruitment to high-risk activism: The case of Freedom Summer. American Journal of Sociology, 92(1), 64-90. Retrieved from: http://www.jstor.org/stable/2779717

McCarthy, J. D., and Zald, M. (1977). Resource Mobilization and Social Movements: A Partial Theory. American Journal of Sociology, 82, 1212-41.

McGarty, C., Bliuc, A. M., Thomas, E. F., \& Bongiorno, R. (2009). Collective action as the material expression of opinion-based group membership. Journal of Social Issues, $65(4), 839-857$. 
McKirdy, E. (2014, September 30). 'One country, two systems': how Hong Kong remains distinct from China'. $C N N$. Retrieved from:

https://edition.cnn.com/2014/09/29/world/asia/hong-kong-protestbackgrounder/index.html

Miller, K. I. (2007). Compassionate communication in the workplace: Exploring processes of noticing, connecting, and responding. Journal of Applied Communication Research, 35, 223-245. doi: http://dx.doi.org/10.1080/00909880701434208

Miller, A. D., Cronin, T., Garcia, L.A., Branscombe, R. N. (2009). The relative impact of anger and efficacy on collective action is affected by feelings of fear. Group Processes and Intergroup Relations, 12(4), 445-464. doi:10.1177/1368430209105046

Moss, D. (2014). Repression, response, and contained escalation under "liberalized" authoritarianism in Jordan. Mobilization: An International Quarterly, 19(3), 261-286.

Moore, W. (1998). Repression and dissent: Substitution, context and timing. Journal of Political Science, 42(3), 851-873.

Moore, W. H. (2000). The repression of dissent: A substitution model of government coercion. Journal of Conflict Resolution, 44(1), 107-127. doi: $\underline{10.1177 / 0022002700044001006}$

Moreira, P. L., Rique Neto, J., Sabucedo, J. M. \& Camino, C. P. S. (2018). Moral judgment, political ideology and collective action. Scandinavian Journal of Psychology, 59, 610-620. doi: 10.1111/sjop.12479

Morris, C. (2013, June 16). Turkey unrest: Mass rally for Erdogan amid new clashes. $B B C$. Retrieved from: http://www.bbc.co.uk/news/world-europe-22925619

Moskalenko, S., \& McCauley, C. (2009). Measuring political mobilization: The distinction between activism and radicalism. Terrorism and political violence, 21(2), 239-260. doi:10.1080: 095-16550902765508 
Moss, D. (2014). Repression, response, and contained escalation under "liberalized" authoritarianism in Jordan. Mobilization: An International Quarterly, 19(3), 261-286.

Muller, E.N. (1985). Income, inequality, regime repressiveness, and political violence. American Sociological Review, 50(1), 47-61. doi: 10.2307/2095339

Muller, E. N., \& Weede, E. (1990). Cross-national variation in political violence: a rational action approach. Journal of Conflict Resolution, 34(4), 624-651. doi: $10.1177 / 0022002790034004003$

Mummendey, A., Kessler, T., Klink, A., \& Mielke, R. (1999). Strategies to cope with negative social identity: Predictions by social identity theory and relative deprivation theory. Journal of Personality and Social Psychology, 76(2), 229-245. doi: $10.1037 / 0022-3514.76 .2 .229$

Muthén, L. K., \& Muthén, B. O. (1998). Mplus: The comprehensive modeling program for applied researchers; user's guide [Version 1.0].

Muthén, L., \& Muthén, B. (2007). Mplus 5. Los Angeles: Muthén \& Muthén.

Nepstad, S.E. (2004). Persistent resistance: Commitment and community in the Plowshares Movement. Social Problems, 51(1), 43-60. doi: http://dx.doi.org/10.1525/sp.2004.51.1.43

Nepstad, S.E. (2011). Nonviolent Revolutions: Civil Resistance in the Late $20^{\text {th }}$ Century. Oxford UK: Oxford University Press.

Nepstad, S., \& Smith, C. (1999). Rethinking recruitment to high-risk/cost activism: the case of Nicaragua exchange. Mobilization: An International Quarterly, 4(1), 25-40. doi: 10.17813/maiq.4.1.8152670287r21558

Olson, M. (1968). The logic of collective action. New York: Schocken Books.

Olson, M. (1965). Logic of collective action public goods and the theory of groups. Harvard economic studies, v. 124). Harvard University Press. 
Ondetti, G. (2006). Repression, opportunity, and protest: Explaining the takeoff of Brazil's landless movement. Latin American Politics and Society, 48(2), 61-94. doi:10.1353/lap.2006.0023

Opp, K.D. (1994). Repression and revolutionary action in 1989. Rationality and Society, 6, 101-138. doi:10.1177/1043463194006001007

Opp, K. D. (2009). Theories of political protest and social movements: A multidisciplinary introduction, critique, and synthesis. Routledge.

Opp, K.D., \& Roehl, W. (1990). Repression, micro-mobilization, and political protest. Social Forces, 69(2), 521-547. doi:10.1093/sf/69.2.521

Ortiz, D.G. (2007). Confronting oppression with violence: Inequality, military infrastructure and dissent repression. Mobilization: An International Quarterly Review, 12(3), 219238.

Ortmann, S. (2015). The Umbrella Movement and Hong Kong's protracted democratization process. Asian Affairs, 46(1), 32-50, doi: 10.1080/03068374.2014.994957

Osborne, D., Jost, J. T., Becker, J. C., Badaan, V., \& Sibley, C. G. (2019). Protesting to challenge or defend the system? A system justification perspective on collective action. European Journal of Social Psychology, 49(2), 244-269. doi:

$10.1002 /$ ejsp. 2522

Osborne, D., Smith, H.J., \& Huo, Y.J. (2012). More than a feeling: Discrete emotions mediate the relationship between relative deprivation and reactions to workplace furloughs. Personality and Social Psychology, 38(5), 628-641. doi: $10.1177 / 0146167211432766$

Osborne, D., Yogeeswaran, K., \& Sibley, C. G. (2015). Hidden consequences of political efficacy: Testing an efficacy-apathy model of political mobilization. Cultural Diversity and Ethnic Minority Psychology, 21(4), 533. doi: 10.1037/cdp0000029 
Pierini, M. (2013, June 30). Urban transformation in Turkey. Carnegie Europe. Retrieved from: http://carnegieeurope.eu/2013/06/20/urban-transformation-in-turkey

Preacher, K. J., \& Hayes, A. F. (2008). Asymptotic and resampling strategies for assessing and comparing indirect effects in multiple mediator models. Behavior Research Methods, 40, 879-891. doi:10.3758/BRM.40.3.879

Rad, M. S., Martingano, A. J., \& Ginges, J. (2018). Toward a psychology of Homo sapiens: Making psychological science more representative of the human population. Proceedings of the National Academy of Sciences, 115(45), 11401-11405. https://doi.org/10.1073/pnas.1721165115

Rasler, K. (1996). Concessions, repression and political protest in the Iranian Revolution. American Sociological Review, 61(1), 132-152. Retrieved from: http://www.jstor.org/stable/2096410

Reicher, S. D. (1996). 'The Battle of Westminster': developing the social identity model of crowd behavior in order to explain the initiation and development of collective conflict. European Journal of Social Psychology, 26(1), 115-134.

Reicher, S., Haslam, S. A., \& Hopkins, N. (2005). Social identity and the dynamics of leadership: Leaders and followers as collaborative agents in the transformation of social reality. The Leadership Quarterly, 16, 547-568. doi: http://dx.doi.org/10.1016/j.leaqua.2005.06.007

Renn, O. (1992). Concepts of risk: A classification. In S. Krimsky \& D. Golding (Eds.), Social Theories of Risk (pp. 53-79). West Port, CT: Praeger. Retrieved from: http://elib.uni-stuttgart.de/opus/volltexte/2010/5416/pdf/ren63.pdf.

Roe, R. (2012). What is wrong with mediators and moderators? European Health Psychologist, 14(1), 4-10. 
Ross, C. (2015). State against civil society: Contentious politics and the non-systemic opposition in Russia. Europe-Asia Studies, 67(2), 171-176. doi:10.1080/09668136.2014.1001575

Rubin, D. B. (1976). Inference and missing data. Biometrika, 63(3), 581-592.

Runciman, W. G. (1966). Relative deprivation and social justice: A study of attitudes to social inequality in twentieth-century England. Berkeley: University of California Press

Saab, R., \& Ayoub, M. (2016). The impact of repression threat on collective action: An experimental investigation. Unpublished manuscript.

Saab, R., Tausch, N., Spears, R. \& Cheung, W. (2015). Acting in solidarity: Testing an extended dual pathway model of collective action by third parties. British Journal of Social Psychology, 54(3), 539-560. doi: 10.1111/bjso.12095

Saab, R., Spears, R., Tausch, N., \& Sasse, J. (2016). Predicting aggressive collective action based on the efficacy of peaceful and aggressive actions. European Journal of Social Psychology, 46(5), 529-543. doi: 10.1002/ejsp.2193

Sabucedo J. M., Dono M., Alzate M., Seoane G. (2018). The importance of protesters' morals: moral obligation as a key variable to understand collective action. Frontiers in Psychology, 9, 418. doi: 10.3389/fpsyg.2018.00418

Sabucedo J. M., Dono. M., Grigoryev, D., Gómez-Román, C. \& Alzate, M. (2019). Axiological-Identitary Collective Action Model (AICAM): A new integrative perspective in the analysis of protest. PLOS ONE, 14(6). doi:

10.1371/journal.pone.0218350

Schafer, J. L., \& Graham, J. W. (2002). Missing data: our view of the state of the art. Psychological methods, 7(2), 147. doi: 10.1037//1082-989X.7.2.147 
Sharp, G. (2005). Waging Nonviolent Struggle: 20th Century Practice and 21st Century Potential. Boston, MA: Porter Sargent.

Schock, K (2015a). Civil Resistance Today. Cambridge: Polity Press.

Schock, K. (2015b). Civil Resistance: Comparative Perspectives on Nonviolent Struggle. Minneapolis: University of Minnesota Press.

Schock, K. (2013). The practice and study of civil resistance. Journal of Peace Research. 50, 277-244. doi: 10.1177/0022343313476530

Schwartz, S. H. (1997). Values and culture. In D. Munro, S. Carr, \& J. Schumaker (Eds.), Motivation and culture (pp. 69-84). New York: Routledge.

Simon, B., \& Klandermans, B. (2001). Politicized collective identity. A social psychological analysis. American Psychologist, 56(4), 319-331.

Simunovic, D., Mifune, N., \& Yamagishi, T. (2013). Preemptive strike: An experimental study of fear-based aggression. Journal of Experimental Social Psychology, 49(6), $1120-1123$.

Smith, E. R. (1993). Social identity and social emotions: Toward new conceptualizations of prejudice. In D. M. Mackie \& D. L. Hamilton (Eds.), Affect, cognition, and stereotyping: Interactive processes in group perception (pp. 297-315). San Diego, CA: Academic Press

Smith, C. A., \& Kirby, L. D. (2001). Affect and cognitive appraisal processes. In J. P. Forgas (Ed.), Handbook of affect and social cognition. London: Lawrence Erlbaum Associations.

Smith, H.J., Pettigrew, T.F., Pippin, G.M., \& Bialosiewicz, S. (2012). Relative deprivation: A theoretical and meta-analytical review. Personality and Social Psychology Review 16(3), 203-232. doi:10.1177/1088868311430825 
Smyth, R., Soboleva, I., Shimek, L., \& Sobolev, A. (2013a). Defining common ground: Collective identity in Russia's post-election protests rallies. In Ross. C. (Ed), Systemic and non-systemic opposition in the Russian Federation. Civil society awakens? New York: Routledge.

Smyth, R., Soboleva, I., Shimek, L., \& Sobolev, A. (2013b). A well-organized play: Symbolic politics and the effect of the pro-Putin rallies. Problems of PostCommunism, 60(2), 24-29. doi:10.2753/PPC1075-8216600203

Solak, N., Jost, J., Sümer, N., \& Clore, G. L. (2012). Rage against the machine: the case for system-level emotions. Social and Personality Psychology Compass, 6(9), 674690. doi: 10.1111/j.1751-9004.2012.00456.x

Sombutpoonsiri, J. (2015). Nonviolent action as the interplay between political context and 'insider's knowledge': Otpor in Serbia. In Schock, K. (Ed.), Civil Resistance: Comparative Perspectives on Nonviolent Struggle. Minneapolis: University of Minnesota Press.

Sorensen, M.J. (2008). Humour as a serious strategy of nonviolent resistance to oppression. Peace and Change, 33, 167-190. doi:10.1111/j.1468-0130.2008.00488.x

Spanovic, M., Lickel, B., Denson, T. F., \& Petrovic, N. (2010). Fear and anger as predictors of motivation for intergroup aggression: Evidence from Serbia and Republika Srpska. Group Processes \& Intergroup Relations, 13(6), 725-739. doi: $10.1177 / 1368430210374483$

Stern, P.C., Dietz, T., Abel, T.D., Guagnano, G. A., Kalof, L. (1999). A value-belief-norm theory of support for social movements: The case of environmentalism. Human Ecology Review, 6(2), 81-97. 
Stürmer, S., \& Simon, B. (2004). Collective action: Towards a dual-pathway model. European Review of Social Psychology, 15(1), 59-99. doi:10.1080/10463280340000117

Stürmer, S, Simon, B., Loewy, M., \& Jorger, H. (2003). The dual pathway model of social movement participation: The case of East Acceptance Movement. Social Psychology Quarterly, 66, 71-82. Retrieved from: http://www.jstor.org/stable/3090142

Sutton, J., Butcher, C. R., \& Svensson, I. (2014). Explaining political jiu-jitsu: Institution building and the outcomes of regime violence against unarmed protests. Journal of Peace Research, 51(5), 559-573. doi: 10.1177/0022343314531004

Tajfel, H., \& Turner, J. C. (1979). An integrative theory of intergroup conflict. In W. G. Austin, \& S. Worchel (Eds.), The social psychology of intergroup relations (pp. 3348). Monterey: Brooks/Cole.

Tausch, N., Becker, J., Spears, R., Christ, O., Saab, R., Singh, P., \& Siddiqui, R.N. (2011). Explaining radical group behavior: Developing emotion and efficacy routes to normative and non-normative collective action. Journal of Personality and Social Psychology, 101(1), 129-148. doi:10.1037/a0022728

Thomas, E. F., \& Louis, W. R. (2014). When will collective action be effective? Violent and non-violent protests differentially influence perceptions of legitimacy and efficacy among sympathizers. Personality and Social Psychology Bulletin, 40(2), 263-276. doi: $10.1177 / 0146167213510525$

Thomas, E. F., Mavor, K. I., \& McGarty, C. (2011). Social identities facilitate and encapsulate action-relevant constructs: A test of the social identity model of collective action. Group Processes \& Intergroup Relations, 15(1), 75-88. doi:

\section{$\underline{10.1177 / 1368430211413619}$}


Thomas, E., Mavor, K., \& McGarty, C. (2012). Social identities facilitate and encapsulate action relevant constructs: A test of the social identity model of collective action. Group Processes Intergroup Relations, 15(1), 75-88. doi:10.1177/1368430211413619

Thomas, E., McGarty, C. \& Mavor, K.I (2009). Aligning identities, emotions, and beliefs to create commitment to sustainable social and political action. Personality and Social Psychology Review, 13(3), 194-218. doi:10.1177/1088868309341563

Tetlock, P. E. (2002). Social functionalist frameworks for judgment and choice: Intuitive politicians, theologians, and prosecutors. Psychological Review, 109(3), 451-471. doi: 10.1037//0033-295X.109.3.451

Thomas, E., McGarty, C. \& Mavor, K.I (2009). Aligning identities, emotions, and beliefs to create commitment to sustainable social and political action. Personality and Social Psychology Review, 13(3), 194-218. doi:10.1177/1088868309341563

Tsui, L. (2015). The coming colonization of Hong Kong cyberspace: government responses to the use of new technologies by the umbrella movement. Chinese Journal of Communication, 8(4), 1-9. doi:10.1080/17544750.2015.1058834

Tsung-gan, K. (2017). Umbrella: A Political Tale from Hong Kong. Pema Press: United States.

Turner, J.C., Hogg, M.A., Oakes, P.J., Reicher, S.D., \& Wetherell, M. (1987). Rediscovering the social group: A self-categorization theory. Oxford, UK: Blackwell.

Tweed, D. (2016, September 6). Hong Kong's Autonomy. BloombergQuick Take. Retrieved from: https://www.bloomberg.com/quicktake/hong-kongs-autonomy

United Nations (2014, June 24). Peace plan, unilateral ceasefire offer hope for resolving conflict in Ukraine. Political affairs official tells Security Council. Retrieved from: https://www.un.org/press/en/2014/sc11448.doc.htm 
Van Lange, P. A. M., De Bruin, E. M. N., Otten, W., \& Joireman, J. A. (1997). Development of prosocial, individualistic, and competitive orientations: Theory and preliminary evidence. Journal of Personality and Social Psychology, 73(4), 733-746. doi: $\underline{10.1037 / 0022-3514.73 .4 .733}$

Van Stekelenburg, J. \& Klandermans, B. (2007). Individuals in movements: A social psychology of contention. In C. M. Roggeband \& B. Klandermans (Eds.). The Handbook of Social Movements Across Disciplines (pp. 157-204). New York: Springer.

Van Stekelenburg, J. \& Klandermans, B. (2010). Individuals in movements: A social psychology of contention. In: Roggeband CM and Klandermans B (eds) The Handbook of Social Movements across Disciplines, reprint edn. New York: Springer, pp. $157-204$

Van Stekelenburg, J., Klandermans, B., \& Van Dijk, W. W. (2011). Combining motivations and emotion: The motivational dynamics of protest participation. Revista de Psicología Social, 26(1), 91-104

Van Zomeren, M. (2016). Building a tower of Babel? Integrating core motivations and features of social structure into the political psychology of political action. Advances in Political Psychology, 37, 87-114. doi: 10.1111/pops.12322

Van Zomeren, M. (2013). Four core social-psychological motivations to undertake collective action. Social and Personality Psychology Compass, 7(6), 378-388. doi: $10.1111 / \mathrm{spc} 3.12031$

Van Zomeren, M., Kutlaca, M., \& Turner-Zwinkels, F. (2018). Integrating who "we" are with what "we" (will not) stand for: A further extension of the Social Identity Model of Collective Action. European Review of Social Psychology, 29(1), 122-160. doi: 0463283.2018 .1479347 
Van Zomeren, M., \& Louis, W. R. (2017). Culture meets collective action: Exciting synergies and some lessons to learn for the future. Group Processes and Intergroup Relations, 20(3), 277-284. doi: 10.1177/1368430217690238

Van Zomeren, M., Saguy, T., \& Schellhaas, F.M.H. (2013). Believing in "making a difference" to collective efforts: Participative efficacy beliefs as unique predictor of collective action. Group Processes Intergroup Relations, 16(5), 618-634. doi: $10.1177 / 1368430212467476$

Van Zomeren, Postmes, T., \& Spears, R. (2008). Toward an integrative social identity model of collective action: A quantitative research synthesis of three socio-psychological perspectives. Psychological Bulletin, 134(4), 504-535. doi:10.1037/00332909.134.4.504

Van Zomeren, M., Postmes, T., \& Spears, R. (2012). On conviction's collective consequences: Integrating moral conviction with the social identity model of collective action. British Journal of Social Psychology, 51, 52-71. doi:10.1111/j.2044-8309.2010.02000.x

Van Zomeren, M., Spears, R., Fischer, A. H., \& Leach, C. W. (2004). Put your money where your mouth is! Explaining collective action tendencies through group based anger and group efficacy. Journal of Personality and Social Psychology, 87(5), 649-664. doi:10.1037/0022-3514.87.5.649

Vilas, X., \& Sabucedo, J.M., (2012). Moral obligation: A forgotten dimension in the analysis of collective action. Revista de Psicologia Social: International Journal of Social Psychology, 27(3), 369-375. doi: 10.1174/021347412802845577

Walker, I., \& Smith, H. J. (2002). Relative deprivation: Specification, development, and integration. Cambridge, England: Cambridge University Press. 
Watts, M. W. (2001). Aggressive Political Behavior. Predisposition and Protest Behavior. East and West, Then and Now. In A. Koch, M. Wasmer, \& A. Schmidt (Eds.). Politische Partizipation in der Bundesrepublik Deutschland: Empirische Befunde und theoretische Erklärungen (pp. 109-130). Opladen: Leske Budrich.

Webb, T. L., \& Sheeran, P. (2006). Does changing behavioral intentions engender behavior change? A meta-analysis of the experimental evidence. Psychological bulletin, 132(2), 249. doi: 10.1037/0033-2909.132.2.249

White, R. (1989). From peaceful protest to guerilla war: Micro-mobilization of the provisional Irish Republican Army. American Journal of Sociology, 94(6), 12771302. Retrieved from: http://www.jstor.org/stable/2780960

Wiltfang, G., \& McAdam, D. (1991). The costs and risks of social activism: A Study of Sanctuary Movement activism. Social Forces 69, 987-1010. doi: 10.1093/sf/69.4.987

Wisler, D., \& Giugni, M. (1999). Under the spotlight: The impact of media attention on protest policing. Mobilisation: An International Journal, 4(2), 171-187.

Witte, K. (1992). Putting the fear back into fear appeals: The extended parallel process model. Communication Mono-graphs, 59, 329-349. doi: 00.1080/03637759209376276

Witte, K. (1996). Fear as motivator, fear as inhibitor: Using the extended parallel process model to explain fear appeal successes and failures. In P. A. Andersen \& L. K. Guerrero (Eds.), Handbook of communication and emotion: Research, theory, applications and contexts (pp. 423-450). San Diego, CA: Academic Press.

Wisler, D., \& Giugni, M. (1999). Under the spotlight: The impact of media attention on protest policing. Mobilization: An International Quarterly, 4(2), 171-187. Downloaded from: https://journals.sagepub.com/doi/pdf/10.1177/0022343314531004 
Wright, S. C., Taylor, D. M., \& Moghaddam, F. M. (1990). Responding to membership in a disadvantaged group: From acceptance to collective protest. Journal of Personality and Social Psychology, 58(6), 994-1003. doi:10.1037/0022-3514.58.6.994

Zelinska, O. (2017). Ukrainian Euromaidan protest: Dynamics, causes, and aftermath. Sociology Compass, 12, 1 - 12. doi: 10.1111/soc4.12502

Zimbardo, P. (2007). The lucifer effect: How good people turn evil. New York: Random House.

Zwart, H. (1997). The experience of moral obligation: preparatory notes on behalf of historical ontology of moral subjectivity. In: P. Cobben, L. Heyde (Eds.) How natural is the law? Tilburg: Tilburg University Press, 87-110. 